\title{
La guerra fría, el movimiento estudiantil de 1968 y el gobierno de Gustavo Díaz Ordaz. La mirada de las agencias de seguridad de Estados Unidos*
}

\author{
The Cold War, the 1968 Student Movement \\ and the Government of Gustavo Díaz Ordaz. \\ The Perspective of US Security Agencies
}

\author{
María del Carmen Collado Herrera \\ Instituto de Investigaciones Dr. José María Luis Mora, México \\ ORCID: 0000-0002-6784-0499 \\ ccollado@mora.edu.mx
}

Resumen: Se analiza la percepción de las agencias de seguridad estadunidense sobre el movimiento estudiantil mexicano de 1968, las relaciones de México con Cuba, y, de manera general, con los países del bloque soviético. Las impresiones de estas instancias de seguridad sobre la diplomacia de México con las naciones de la órbita comunista sirven como marco para comprender las ideas encontradas y coincidentes entre los gobiernos de Gustavo Díaz Ordaz y Lyndon B. Johnson sobre el movimiento del 68. Los procesos analizados se dieron en un marco de estrecha colaboración entre ambas administraciones debido a la guerra fría y a la convicción anticomunista que ambos mandatarios compartían. Se aprecia que los informes de seguridad de Estados Unidos -aunque en ocasiones mostraron visiones contradictorias y tenían diversos niveles de confiabilidad, según el momento y la intención con la que fueron elaborados- no secundaron la versión oficial del régimen sobre el 68.

* Agradezco a la Llilas Benson Latin American Studies and Collections de la University of Texas la beca que me concedió en 2014, gracias a la cual pude consultar los National Security Files de la Lyndon B. Johnson Library con los cuales se nutre una parte de este trabajo. 
Palabras clave: movimiento estudiantil; agencias de seguridad; Díaz Ordaz; Estados Unidos; guerra fría.

Abstract: This paper analyzes US security agencies' perception of the 1968 Mexican student movement and Mexico's relations with Cuba and Soviet bloc countries in general. These security agencies' perception of Mexico's diplomacy with countries in the communist orbit serve as the framework for understanding the opposing and overlapping perceptions of the governments of Gustavo Díaz Ordaz and Lyndon B. Johnson of the '68 movement. The processes analyzed occurred within a framework of close cooperation between the two administrations because of the Cold War and the anti-Communist views shared by the two leaders. The article shows that although they sometimes expressed contradictory views and had varying levels of reliability, depending on the timing and purpose with which they were written, US security reports did not support the regime's official version of events in '68.

Key words: student movement; security agencies; Díaz Ordaz; U.S; Cold War.

Fecha de recepción: 6 de julio de 2016 Fecha de aceptación: 11 de octubre de 2016

E objetivo de esta investigación es mostrar cómo fue percibido por los aparatos de seguridad estadunidenses el movimiento estudiantil de 1968 y la política exterior mexicana hacia Cuba y los países del Este europeo, todo enmarcado en el contexto de la guerra fría que experimentaba uno de sus conflictos más álgidos en la guerra de Vietnam. Los materiales producidos por las diferentes instancias de seguridad nacional estadunidense son un mirador privilegiado para calibrar la actuación del gobierno mexicano en una etapa signada por la gran colaboración y coincidencia de ambos vecinos en torno a la necesidad de contener el avance del comunismo.

La primera parte de este trabajo, a manera de marco introductorio, aborda la coincidencia anticomunista de México y Estados Unidos y la tolerancia del segundo con la diplomacia de cariz independiente que el primero había ejercido con Cuba, subrayando las percepciones de Estados Unidos. Se toca el doble juego de la política exterior mexicana hacia la isla, con quien el gobierno mantenía relaciones, al tiempo que le pasaba información y le hacía favores a las oficinas de seguridad estadunidenses y altos funcionarios del

\section{(ㅇ)(1) $(2$}


gobierno de México mantenían vínculos con la Central Intelligence Agency (CIA). Asimismo, se analizan las evaluaciones que realizó la ciA sobre el gobierno mexicano.

La segunda parte de este estudio analiza la visión de Estados Unidos sobre el movimiento estudiantil de 1968 en contraste con la del presidente Gustavo Díaz Ordaz y su grupo más cercano. Con esto último pretendo desentrañar las percepciones, en ocasiones coincidentes y en otras diferentes, de las administraciones de Lyndon B. Johnson y de Díaz Ordaz y abonar a la comprensión de un movimiento social desde las esferas del poder. La insistencia del gobierno mexicano de culpar a comunistas mexicanos o del exterior de haber generado y dominado el movimiento sin ofrecer evidencia, contrasta con las relaciones amistosas que México mantenía con los países del bloque soviético.

Las ideas que sustentan este análisis son que la diplomacia relativamente independiente de Washington que México ejercía hacia Latinoamérica y otras zonas del globo era utilizada para conseguir mayores apoyos y convivir sin ser avasallado por su poderoso vecino. Le servía además para apuntalar el consenso nacionalista, al satisfacer a la izquierda dentro y fuera del PRI y mantener a raya a la derecha. Esta situación era compensada con una amplia colaboración en el ámbito reservado de la seguridad, porque tanto México como Estados Unidos coincidían en su rechazo a la expansión del comunismo del bloque soviético que, a través de Cuba, se asomaba en el hemisferio. No obstante, el gobierno estadunidense confundía a veces el nacionalismo revolucionario, traducido en una diplomacia independiente, con el comunismo, y ello generaba roces y malos entendidos. Pese a la profunda convicción anticomunista de los gobiernos de Díaz Ordaz y Johnson, y a la amplia colaboración de ambos, las agencias de seguridad estadunidenses no secundaron la versión del gobierno mexicano de que el movimiento estudiantil de 1968 fue resultado de la manipulación de agentes soviéticos o cubanos infiltrados. Dadas las amplias actividades y recursos desplegados por Estados Unidos y sus diferentes oficinas de seguridad, incluida la estación local de la CiA, para vigilar lo que sucedía en Latinoamérica, registrar lo que se fraguaba en las embajadas de Cuba, la URSS, otras representaciones del bloque socialista y a los revolucionarios latinoamericanos exiliados en México, sus interpretaciones sobre el movimiento estudiantil resultan muy valiosas y útiles para contrastarlas con las de Díaz Ordaz y ampliar así la perspectiva de análisis de ese momento histórico.

Si bien no pretendo hacer una revisión historiográfica exhaustiva por razones de espacio, creo conveniente retomar algunas posiciones de otros au-

\section{()(1) $\$$}


tores como referencia básica para ubicar este trabajo. La historiografía sobre las relaciones entre México y Estados Unidos (Riguzzi y De los Ríos, 2012, pp. 316-335) concuerda en que a partir de la segunda guerra mundial se amplió la colaboración entre ambos países a través de préstamos y convenios de diferente índole. Mario Ojeda (1984, pp. 93-94) afirma que existió una relación especial entre ambos vecinos durante la guerra fría basada en la cooperación bilateral en temas de interés, tolerancia a la relativa independencia diplomática de México a cambio de su apoyo en lo fundamental, en virtud de que la estabilidad política de su vecino era crucial para su seguridad. Una vez que salieron a la luz los documentos desclasificados de la cia y otras oficinas de seguridad a partir de 1998, quedó clara la doble factura de la política exterior mexicana: cierta independencia diplomática respecto a Estados Unidos y alianza y colaboración en temas de seguridad (Herrera y Santa Cruz, 2011, pp. 351-353; Riguzzi y De los Ríos, 2012, pp. 204-408). La historiografía dedicada a las relaciones de México con Cuba y el bloque comunista afirma que estas se basaron en el respeto a la autodeterminación, pero a su vez reconoce la doble cara de las relaciones de ambas naciones (Rojas y Covarrubias, 2011, pp. 146-148). Por su parte, la política exterior como legitimadora del régimen ha sido abordada por varios autores entre quienes podemos destacar a Lorenzo Meyer (2010, p. 204) y Soledad Loaeza (1988, pp. 200-201).

El movimiento del 68 ha sido tratado en una amplia gama de escritos literarios, periodísticos, históricos y científico sociales, pero aún hacen falta más investigaciones académicas (Jiménez, 2011 y Rodríguez, 2003, pp. 180-181). Ariel Rodríguez Kuri señala que en México ha prevalecido una historia más volcada a la recuperación de la memoria con un afán didáctico, en tanto que Héctor Jiménez Guzmán concluye que lo testimonial, de tono reivindicativo, escrito desde la prisión, ha sobredeterminado al resto de la producción historiográfica.

Entre los trabajos que han abordado el 68, introduciendo la variable estadunidense, se encuentra un pequeño grupo que corresponsabiliza al país vecino del norte de la represión al movimiento. Tal es el caso de Pablo Moctezuma Barragán (2008) y el documental de Carlos Mendoza (2007) 1968. La conexión americana, del Canal 6 de julio. Si bien ambos reconocen que las causas del movimiento fueron internas, inmersos en una historiografía maniquea que presenta a México como el campo de batalla de la guerra fría, atribuyen al imperialismo estadunidense una corresponsabilidad en la violencia con la que el Estado mexicano desarticuló al movimiento. Estas interpretaciones, aunque provienen de las izquierdas, se vinculan de algu-

\section{()(1)(3)}


na manera con los "escritos de la conjura", una corriente historiográfica de derechas que secundó la interpretación oficial de que el movimiento resultó de una manipulación de agentes comunistas externos (Jiménez, 2011, pp. 3038). Si bien estas obras se sitúan en el polo opuesto a las primeras, al acentuar esos factores externos se articulan en torno a la visión de México como una víctima de la guerra fría.

Desde una perspectiva mucho más compleja Jaime M. Pensado analiza el papel de la historiografía conservadora en la construcción histórica del 68. Su texto tiene la virtud de explicar los acontecimientos en el marco de las movilizaciones estudiantiles de la década de 1960, pero también tiene la limitación de no haber considerado el control que el gobierno ejerció sobre la prensa, su principal fuente. La interpretación conservadora presentó a los estudiantes como víctimas y así permitió, afirma Pensado, que cerrara la herida dejada por el movimiento del 68, aunque dejando una cicatriz. Asevera, en coincidencia con Jiménez, que dicha corriente fue predominante en los años posteriores a Tlatelolco, y presentó a la juventud como víctima de las manipulaciones del comunismo internacional, de las izquierdas "apátridas" y de las influencias destructoras de la nacionalidad, representadas por la contracultura estadunidense de los sesenta (Pensado, 2013, pp. 201-234).

Por su parte, Abraham Trejo Terreros (2012), en su artículo "La mirada de Washington en el movimiento estudiantil de 1968" (pp. 111-114), basado en fuentes de seguridad nacional y de historia diplomática, se centra en mostrar si Estados Unidos cambió su percepción sobre la estabilidad mexicana y no analiza las divergencias entre las interpretaciones de las agencias de seguridad estadunidenses y las del gobierno mexicano.

Especial mención merece el libro de Sergio Aguayo (1998) 1968. Los archivos de la violencia, en donde se analiza el movimiento en el marco de un Estado autoritario, represor de las corrientes de izquierdas. El autor investiga la actitud del gobierno estadunidense y la cia durante el movimiento, así como la de las agencias de seguridad mexicanas. Aunque sus conclusiones son similares a las sostenidas en el presente artículo, desde que publicó este libro se ha desclasificado mucho material secreto en Estados Unidos. ${ }^{1}$ El texto de Aguayo (1998, pp. 15-17) tiene una gran riqueza documental derivada de la consulta de fuentes de seguridad estadunidenses y mexicanas, del Archivo de la Secretaría de Relaciones Exteriores y de las entrevistas realizadas.

${ }^{1}$ A este respecto pueden verse los materiales del National Security Archive que ha venido desclasificando documentos en el año 2000, 2003, 2006 y de la CiA en 2015.

\section{()ㅜ(1) $\$$}


Otro texto destacado que utilizó fuentes de seguridad estadunidenses, cubanas y mexicanas es el de Renata Keller (2015), Mexico's Cold War. Para la autora el 68 está enclavado en la propia guerra fría que México encaraba en su oposición a los movimientos sociales asociados a las izquierdas locales, más allá de la confrontación ideológica Este-Oeste de la guerra fría. Así el 68 es presentado como una más de estas movilizaciones izquierdistas opositoras al priismo, inmersa en la confrontación ideológica del Estado, quien defendía el legado de la revolución mexicana, contra la revolución cubana, que inspiraba a los grupos socialistas mexicanos (Keller, 2015, pp. 202-218 y 231). Donald Hodges y Ross Gandy (2002) dedicaron un libro a los movimientos populares y al autoritarismo mexicanos en el que hacen una interpretación desde las izquierdas que coincide con la que prevalece entre los autores mexicanos, al situar al movimiento como parte de una larga lucha de resistencia al poder. Asimismo, explica la decisión del gobierno mexicano de culpar a comunistas infiltrados del movimiento como una estrategia para cubrir sus propios errores. Por su parte, Eric Zolov (2002), quien utiliza fuentes mexicanas y estadunidenses en su clásico libro del movimiento estudiantil, hace una interpretación culturalista que rebasa el ámbito político de la confrontación y pone el acento en la influencia de la contracultura del país vecino del norte y en la propia que se generó en México. En un artículo posterior Zolov (2003) analiza el impacto del movimiento en las relaciones México-Estados Unidos a partir de la prensa y de fuentes del gobierno estadunidenses. Zolov concluye que el movimiento no cambió la visión de Estados Unidos de que su vecino tenía un gobierno fuerte y estable, crucial para su política de contención del comunismo en Latinoamérica. Un libro de Kevin Witherspoon (2008) sobre la mirada internacional de México alrededor de los juegos olímpicos de 1968, concluye de manera ingenua que, pese a las menciones encontradas en los documentos del Departamento de Estado sobre actividades comunistas en México, Washington optó por apoyar la represión del gobierno mexicano para apuntalar a un aliado crucial en la confrontación de la guerra fría. La biografía de Jefferson Morley (2010) sobre Winston Scott, quien fue director de la estación local de la CIA en México durante trece años, aporta información sobre la trayectoria de Scott y su participación en actividades de espionaje y encubiertas. Morley concluye acertadamente que la cercanía entre el gobierno mexicano y la ciA local fue tan grande que Scott fue incapaz de enviar información independiente de la que arrojaban los servicios mexicanos locales al informar sobre el 68, pero sobre todo sobre la matanza de Tlatelolco, y que, al ser confronta-

\section{()(1) $(2$}


do por el Departamento de Estado terminó por distanciarse de sus informes preliminares. Una de las limitaciones de este texto es que sobredimensiona la influencia de Scott y, por ende, de la CIA, en las políticas mexicana y estadunidense, omitiendo que la política exterior de un país tiene objetivos mucho más amplios que los del espionaje. Por último, Kate Doyle, directora del Mexico Project del National Security Archive, afirma que la embajada estadunidense emitió informes confusos sobre el movimiento estudiantil, contaminada, al igual que la ciA, por la versión de las oficinas de seguridad mexicanas. No obstante, días después de la represión del 2 de octubre los informes de la cia local desmintieron esta versión. ${ }^{2}$

Si bien existen varios trabajos que utilizan las fuentes estadunidenses y las de seguridad para explicar lo sucedido en el México del 68, el presente artículo plantea preguntas distintas. Pretendo poner a prueba la interpretación oficial mexicana del movimiento a partir de la disección de los informes de las agencias de seguridad estadunidenses y con ello contribuir a la historiografía sobre el tema. Las fuentes primarias en las que se fundamenta este trabajo son los National Security Files de la Lyndon B. Johnson Library, ${ }^{3}$ el Mexico Project del National Security Archive de la George Washington University, los Foreign Relations of the United States 1964-1968, vol. xxxI, South and Central America, Mexico, del Department of State, la John F. Kennedy Oral History Collection de la John F. Kennedy Library y The President's Daily Briefs de la ciA.

\section{EL GRAN ESCENARIO}

Una cauda de oficinas y funcionarios de inteligencia estadunidenses se ha ocupado de reportar las cosas que les parecen relevantes en su país vecino del sur. Conforme han variado los escenarios nacionales e internacionales de las partes involucradas, han cambiado los intereses y las miradas sobre lo que es importante para el gobierno en Washington.

${ }^{2}$ Doyle, Tlatelolco Masacre. 10 de octubre de 2003. National Security Archive, Mexico Project. The Tlatelolco Masacre, Washington, D. C. (en adelante NSA, MP, TM). Recuperado de http://nsarchive.gwu.edu/NSAEBB/NSAEBB99

${ }^{3}$ Grosso modo, el fondo consultado tiene informes del Departamento de Estado, la embajada de México, la estación mexicana de la ciA, documentos elaborados por las oficinas de la CIA en Washington y los expertos en seguridad de la Casa Blanca.

\section{()(1) $\$$}


A partir de las resoluciones de la Internacional Comunista de 1935, que creó el Frente Popular, Estados Unidos se preocupó por la expansión de las actividades comunistas en Latinoamérica e instruyó al Federal Bureau of Investigation (FBI), fundado en 1908, y dependiente entonces del Departamento del Tesoro, para que vigilara las acciones de los comunistas y se hiciera cargo de las actividades de inteligencia y contrainteligencia en el hemisferio occidental. El FBI se integró al Departamento de Justicia en 1935 y abrió una oficina en México en 1939 (Morley, 2010, p. 122). Por su parte, el secretario de Estado pidió a sus embajadas y consulados en la región que reportaran los movimientos de los grupos sospechosos. El Special Intelligence Service fue creado en 1940 y, entre ese año y marzo de 1947, envió agentes a países latinoamericanos y del Caribe además de reclutar informantes y espías (Raat, 1987, p. 629).

Como es sabido, en 1947, durante la administración de Harry S. Truman, fue creada la ciA, con lo cual perdieron preeminencia el ejército y el Departamento de Estado en las labores de inteligencia y contrainsurgencia. No obstante, cinco años más tarde, en 1952, fue creada la National Security Agency que se hizo cargo de los aspectos tecnológicos más complejos, operaba como parte del Departamento de Defensa y rendía informes al director nacional de Inteligencia. Con ello se restauró la importancia de los militares en estos ámbitos.

Así, cuando llegamos a la década de los sesenta, el aparato de inteligencia estadunidense estaba plenamente desarrollado, realizaba operaciones de espionaje, contraespionaje y diversas actividades encubiertas para interferir en los asuntos internos de diferentes países. Resulta revelador que el director de la oficina de la cia en México, Winston Scott, permaneció en este país durante trece años, entre 1956 y 1969, y tuvo relaciones muy cercanas, casi amistosas, con los presidentes, los secretarios de Gobernación y los funcionarios de seguridad más importantes en México (Riguzzi y De los Ríos, 2012, p. 409). La estación de la ciA en México creció por la exigencia de la guerra fría de vigilar las actividades comunistas en América Latina. México era un lugar destacado porque daba asilo a disidentes de la región y porque la URSS y varios países del Este tenían embajadas desde donde realizaban espionaje. Scott montó una red de inteligencia llamada LITEMPo en 1960, que reclutó a doce altos funcionarios. Está documentado que Gustavo Díaz Ordaz, como secretario de Gobernación de Adolfo López Mateos, era LITEMPO-2, Luis Echeverría Álvarez, subsecretario de Gobernación, LITEMPo-8, Fernando Gutiérrez Barrios, subdirector de la Dirección Federal de

\section{()(1) $(3$}


Seguridad, LitemPo- $4^{4}$ y, de acuerdo con Jefferson Morley (2010, p. 130), Adolfo López Mateos, antes de asumir la presidencia, también formó parte de esta red con el nombre de LITENSOR. La colaboración entre la CIA y estos funcionarios era muy amplia. Un ejemplo de estos intercambios lo constituye la información que México les daba sobre los cubanos que estaban solicitando visas mexicanas en La Habana, personajes que realizaban actividades de espionaje en el país o relacionados con actividades de insurgencia en otras naciones de América Latina, y en general lo que era denominado como "información sensible", tanto para el gobierno de Estados Unidos como para el de México, evitando así que circulara por los canales protocolarios. ${ }^{5}$ A su vez, cuando Díaz Ordaz se convirtió en presidente, Scott entregaba a Los Pinos un resumen diario de inteligencia recabado por la estación de la cia en la ciudad de México (Morley, 2010, p. 345).

Sería simplista suponer que la colaboración sólo era resultado de que estos informantes de alto nivel estaban en la nómina de la agencia o que la colaboración de estos prominentes funcionarios implicaba que la CIA era el poder invisible que guió los destinos del país, como lo afirma Mendoza (2007) en su documental 1968. La conexión americana y lo sugieren Moctezuma (2008), Martín Moreno ${ }^{6}$ y el propio Morley (2010, pp. 131-132) en su biografía de Scott. Los pagos y/o regalos hechos a los altos funcionarios, aun si fueron altos, no eran el principal ingrediente de la colaboración; esta derivaba de la profunda convicción anticomunista compartida por las autoridades de ambos países. La necesidad de la seguridad nacional mexicana de tener información cabal sobre las actividades subversivas en el país era también otra razón para mantener abierto este canal de indagación. Así, tanto el gobierno de Estados Unidos como el de México se beneficiaban de los intercambios de sus pesquisas. En este último también operaban espías soviéticos y cubanos con la tolerancia del gobierno. Esta tolerancia, sumada a la que se tenía con los aparatos de espionaje estadunidenses, brindaba a México una

${ }^{4}$ Electronic Briefing Book No. 204, 18 de octubre de 2006. LITEMPO: The CIA's Eyes on Tlatelolco. NSA, MP, L. Recuperado de http://nsarchive.gwu.edu/NSAEBB/NSAEBB204/ index.htm. LITEMPO/ Operational Report, 1-31 de octubre de 1963, NSA, MP, L. Recuperado de http://nsarchive.gwu.edu/NSAEBB/NSAEBB204/3.pdf

${ }^{5}$ Secret report excerpts. 16 de noviembre de 1978. NSA, MP, L. Recuperado de http:// nsarchive.gwu.edu/NSAEBB/NSAEBB204/1.pdf

${ }^{6}$ Moreno, "El ejército jamás disparó", Excélsior, 11 de noviembre de 2011. Recuperado de http://www.excelsior.com.mx/opinion/2011/11/11/francisco-martin-moreno/782769

\section{()(1) $\$$}


seguridad de que los países implicados evitarían desestabilizar a su régimen (Iber, 2014). ${ }^{7}$

\section{VECINOS CERCANOS}

Con la llegada de Johnson a la presidencia, en noviembre de 1963, luego del asesinato de John F. Kennedy, se estrecharon las relaciones entre ambos vecinos; ningún otro país latinoamericano recibió tanta atención personal de parte del texano (Niemeyer, 1986, p. 185). Las relaciones se habían enfriado entre 1961 y 1962 porque México no secundó la diplomacia de Estados Unidos hacia Cuba (Cid, 1998, p. 318). Aunque la política exterior mexicana se había distanciado de las posturas estadunidenses al menos desde el porfiriato, durante la guerra fría fue mal recibido el acercamiento con el Movimiento de los Países No Alineados (MPNA) y con la Francia de Charles de Gaulle. La ambigüedad de México con el MPNA preocupó a la diplomacia estadunidense, que presionó al máximo para que México no asistiera a las reuniones fundacionales en 1961. La indeterminación sirvió a López Mateos para profundizar su capacidad de negociación con Estados Unidos, de quien recibió ventajosos préstamos, así como de organismos multilaterales, de gran utilidad para solventar las dificultades fiscales que encaraba (Pettinà, 2016). Asimismo, la simpatía del ejecutivo mexicano por la revolución cubana encendió los focos rojos en Washington. No obstante la autonomía que en la diplomacia abierta que México exhibía hacia Cuba irritaba sobremanera al gobierno de Kennedy, este aceptó finalmente la disensión, pues en el ámbito de la seguridad nacional, de carácter reservado, ambos gobiernos coincidían plenamente en su anticomunismo. ${ }^{8}$ Johnson comprendía mejor la postura mexicana y como vicepresidente intervino para que mejoraran las relaciones

7 P. Iber, "Paraíso de espías. La ciudad de México y la guerra fría”, Nexos, abril de 2014. Recuperado de http://www.nexos.com.mx/?p=20004\#ftn4

${ }_{8}$ México compartió con la cia la lista de viajeros hacia Cuba, permitió que instalara una cámara en el aeropuerto para filmar a todos los que llegaban desde la isla y negoció la salida de cubanos que deseaban irse a Estados Unidos. Mexico City Station History, Secret report (excerpts). 16 de noviembre de 1978. NSA, MP, L. Washington, D. C. Recuperado de http://nsarchive.gwu.edu/NSAEBB/NSAEBB204/1.pdf. Operational Report, Dispatch from the Chief of Station, Mexico City, LITEMPO. 1 al 30 de septiembre de 1963. NSA, MP, L. Recuperado de http://nsarchive.gwu.edu/NSAEBB/NSAEBB204/8.pdf. Secret Report, 25 de noviembre de 1963. NSA, MP, L. Recuperado de http://nsarchive.gwu.edu/NSAEBB/NSAEBB204/9.pdf.

\section{()(1) $(3$}


entre los dos vecinos. ${ }^{9}$ Por ello, ya en la Casa Blanca, durante una conversación telefónica con Thomas Mann, quien había sido embajador en México entre 1961 y 1963, hasta que fue nombrado por Johnson secretario de Estado adjunto para Asuntos Interamericanos, el presidente le dijo que quería "al mejor estadunidense" al frente de la embajada en México. Consideraba que ellos habían sido desagradables con los mexicanos y para arreglar las cosas prefería a un amigo suyo en ese puesto, a alguien que velara por sus intereses, se condujera como un director, que fuera "endiabladamente capaz", "joven y carismático". ${ }^{10}$ Así llegó Fulton Freeman a la representación mexicana; previamente se había desempeñado como embajador en Colombia en una época compleja. Producto de la importancia que dio a la relación con su vecino del sur, el texano se entrevistó dos veces con López Mateos y siete con Díaz Ordaz en los poco más de cinco años que fue presidente entre noviembre de 1963 y enero de 1969 (Suárez, 1998, pp. 71-128). Esta importancia decreció en la medida en que el conflicto con Vietnam cobró relevancia.

La cIA realizaba análisis rutinarios sobre la estabilidad política de su vecino, la cual lo diferenciaba del resto de Latinoamérica. Dicha estabilidad aseguraba la paz y la seguridad de la frontera sur de Estados Unidos durante la guerra fría y, a cambio de ella, Washington toleraba al régimen autoritario mexicano y lo apoyaba, pese a eventuales roces (Meyer, 2004, pp. 96-97). Uno de los primeros informes de la CIA durante el gobierno de Johnson se dedicó a las elecciones presidenciales en México en 1964, calificadas como un evento que no alteraría la política ni la economía. El candidato del PRI, Gustavo Díaz Ordaz, era visto como un "moderado" que no cambiaría la orientación de la política interior ni internacional. Seguramente continuaría con su política exterior "independiente" en relación con Cuba, el comercio internacional y el desarme, asuntos en los cuales en ocasiones estaba en desacuerdo con Estados Unidos. Reconocía, sin embargo, que el gobierno sería

${ }_{9}$ Carrillo Flores, A. (2 julio 1969). Entrevista a Antonio Carrillo Flores/entrevistador: Dennis O'Brien. John F. Kennedy Oral History Collection, John F. Kennedy Library, Washington, D. C. p. 25-26. Recuperado de http://www.civilrights.jfklibrary.org/Asset-Viewer/ Archives/JFKOH-AC-01.aspx

10 Telephone Conversations between President Johnson and the Assistant Secretary of Inter-American Affairs (Mann). Washington, 25 de enero de 1964, 12:20 pm. Documento 345. Department of State, Office of the Historian, Foreign Relations of the United States 19641968, vol. xxi, South and Central América, México (Washington D. C.) (En adelante DS, OH, SCAM). Washington, D. C. Recuperado de http://history.state.gov/historicaldocuments/ frus1964-68v31/d345

\section{()(1) $(3$}


pro estadunidense. ${ }^{11}$ El informe abundaba en que la tradicional estabilidad de México no se vería alterada por los esfuerzos de los izquierdistas que estaban disgustados por la candidatura de un moderado. Bajo el dominio del partido oficial, afirmaba, el gobierno gastaba sumas considerables en la aplicación de los preceptos "socialistas" de la revolución mexicana, a la vez que mantenía su pragmatismo, ya que su "orientación desafía cualquier definición convencional". ${ }^{12}$

En relación con la lucha contra el comunismo, el informe de la CIA aclaraba que mientras Díaz Ordaz fue secretario de Gobernación batalló con mano dura contra el comunismo y, por tanto, se esperaba que continuara con esta línea como presidente. ${ }^{13}$ Tenía claro que el Partido Popular Socialista era subsidiado parcialmente por el gobierno para asegurar la división de la izquierda y a través de él o de Vicente Lombardo Toledano recibía información sobre algunas actividades de los izquierdistas.

De acuerdo con este informe, la mayor influencia comunista estaba en la Secretaría de Relaciones Exteriores y en la Secretaría de Educación Pública (SEP). La principal fuerza "subversiva" provenía de organizaciones culturales dirigidas por marxistas y comunistas incrustados en las oficinas del gobierno, del sistema educativo y la prensa. ${ }^{14}$ En este punto se advierte la incapacidad de la cia para comprender que la independencia en política exterior de México, tal como su acercamiento con el MPNA, su proximidad con países que Estados Unidos veía como potenciales enemigos, su apoyo a la firma del Tratado para la Proscripción de las Armas Nucleares en América Latina y las relaciones que en lo público mantenía con Cuba, así como el control federal sobre la educación, se relacionaban con el nacionalismo que daba cohesión

${ }^{11}$ CiA. Survey of Latin America, 1 de abril de 1964, caja 1, fólder 9, vol. 1, 4/64, f. 152. Lyndon B. Johnson Library. Material at the LBJ Library Pertaining to Latin America and the West Indies. National Security File, Contry File, Latin America-Mexico, Austin, Texas (en adelante LBJ, NSF, CFLAM).

${ }_{12}$ CIA. Survey of Latin America. 1 de abril de 1964, caja 1, fólder 9. vol. 1, 4/64, 152. LBJ, NSF, CFLAM.

${ }^{13}$ Esto se aprecia también en otro informe de oficina de la Casa Blanca. Meeting of Presidents Johnson and López Mateos in California, 20-22 de febrero de 1964. White House, secret papers. Documento 37, NSA, MP, L. Recuperado de https://www2.gwu.edu/ nsarchiv/ NSAEBB/NSAEBB124/doc37.pdf

${ }^{14}$ La paranoia anticomunista hacía que muchas personas que manifestaban su rechazo a la política intervencionista de Estados Unidos fueran consideradas por Washington como un peligro. Así sucedió con Carlos Fuentes, a quien por pertenecer supuestamente al PCM y ser de izquierdas se le había negado la visa. Memorandum for the President. 13 de mayo de 1964, caja 59, fólder 2, 128. LBJ, NSF, CFLAM.

\section{()ㅜ(1) $\$$}


interna y legitimidad al Estado que, por estas mismas razones, defendía su derecho a dictar el contenido de la educación básica. La incomprensión de las razones que movían la política exterior mexicana explica que la cia viera a la Cancillería como una institución con gran influencia comunista, pues a Estados Unidos siempre se le dificultó comprender que el nacionalismo mexicano no era equivalente al comunismo. Asimismo, es posible que viera a la SEP como una oficina influida por aquella ideología, como un resabio de la querella por la educación que se desató en 1960 por parte de las derechas, cuando se creó el libro de texto gratuito, la cual se engarzó con la campaña anticomunista lanzada por la Iglesia católica mexicana al año siguiente.

Más adelante, el informe señalaba que México era un punto de tránsito importante entre Cuba y Latinoamérica y era "La Meca" de los comunistas centroamericanos y otros exiliados políticos. Por su geografía, su tolerancia política y la facilidad para contrabandear armas se le consideraba una base relevante de actividad subversiva. "Las embajadas comunistas en México (soviética, polaca, checa, yugoslava y cubana) evidentemente desempeñan un papel muy importante en conducir esta subversión, incluyendo la actividad dirigida contra los intereses de seguridad de Estados Unidos." ${ }^{15}$ Tanto los cubanos como los integrantes del bloque comunista apoyaban la sedición desde sus embajadas en contra de Estados Unidos y otros países, pero no contra México para no provocar la irritación del régimen y la limitación a sus actividades de espionaje. Según sus cálculos, el Partido Comunista Mexicano (PCM) tenía pocos militantes y era débil, por lo que su potencial revolucionario era muy limitado. Si durante el régimen de López Mateos la preocupación estadunidense rondó la idea de limitar el avance de las izquierdas en el país (Meyer, 2010, pp. 226-227), con la llegada de su sucesor quedó en claro que las dos administraciones compartían su rechazo al comunismo.

En contraposición, a la cia le preocupaba la situación del campo, la pobreza y el atraso de la mayor parte de los campesinos, que se mantenía a nivel de subsistencia, pese a los esfuerzos de López Mateos en repartir tierras. El abandono de este sector, señalaba, había provocado el crecimiento del descontento campesino manifestado en invasiones de tierras y estallidos de violencia. La preocupación por el campo se relacionaba con la inquietud de que se convirtiera en el caldo de cultivo de una revolución. La conclusión de este abultado informe sobre la situación internacional mexicana era que la relación de Méxi-

15 CIA. Survey of Latin America. 1 de abril de 1964, caja 1, fólder 9, vol. 1, 4/64, 153. LBJ, NSF, CFLAM.

\section{()(1) $(9$}


co con el régimen de Castro se había enfriado, había caído el comercio, limitándose a medicinas y comida, pero prevalecía el temor de que México estableciese relaciones diplomáticas con China. ${ }^{16}$

Johnson envió a Thomas C. Mann, quien ya desempeñaba el cargo de subsecretario de Estado para Asuntos Económicos, y al embajador en México Freeman en una misión especial con el presidente el 31 de diciembre de 1965. Aparentemente Johnson le pidió al mexicano que se reuniera con los representantes diplomáticos del bloque socialista y abordara el conflicto de Estados Unidos en Vietnam y su interés por alcanzar la paz. Para ese momento el gobierno estadunidense había escalado la guerra en el país del sudeste asiático. Luego de la resolución del Congreso sobre el golfo de Tonkín en agosto de 1964, envió más tropas que para marzo de 1965 ya llegaban a 100000 hombres, y había iniciado el bombardeo aéreo en Vietnam del Norte (Brinkley, 2003, p. 963). Díaz Ordaz se ofreció a hablar con el embajador soviético y el polaco, como se lo había sugerido su canciller Antonio Carrillo Flores, pero también dijo que lo haría con el de Checoeslovaquia y Yugoslavia, países que él creía estaban interesados en evitar un conflicto a gran escala. ${ }^{17}$ Los enviados aseguraron al mexicano que Johnson y el secretario de Estado, Dean Rusk, habían estado buscando discretamente una salida pacífica al conflicto por muchos meses y que creían que México podría influir en este sentido. Estados Unidos quería aprovechar la postura mexicana de respaldar una salida pacífica al conflicto de Vietnam (Torres, 2010, p. 175).

El mexicano aprovechó esta ocasión para subrayar el apoyo de su gobierno a Estados Unidos y sus coincidencias ideológicas. Dijo: "México tiene lazos geográficos y económicos con Estados Unidos, ideales iguales y una definición compartida de sus valores." Hizo una declaración contra la China maoísta y señaló que "él creía que China comunista representaba la mayor amenaza a la paz mundial. Era agresiva e irresponsable y no tenía respeto por el valor de la vida humana. De hecho [este país] podría dar la bienvenida a una guerra que redujera su población en doscientos millones porque eso dejaría más comida disponible para el resto." ${ }^{18}$ El contenido de esta reunión revela la cercanía que alcanzaron las relaciones entre México y Estados Uni-

${ }^{16}$ CIA. Survey of Latin America. 1 de abril de 1964, caja 1, fólder 9, vol. 1, 4/64, 156. LBJ, NSF, CFLAM.

${ }^{17}$ Memorandum of conversation. 31 de diciembre de 1965, caja 59, fólder 1,102 ${ }^{\mathrm{a}}$. LBJ, NSF, CFLAM.

${ }_{18}$ Memorandum of conversation. 31 de diciembre de 1965, caja 59, fólder 1, 102 ${ }^{\mathrm{a}}$. LBJ, NSF, CFLAM.

\section{()(1) $\$$}


dos, quien no dudaba en mover la ficha mexicana en el conflicto Este-Oeste confiado en el fuerte anticomunismo de ambas administraciones y en que la independencia diplomática que ostentaba en lo público le confería prestigio internacional.

Durante la gestión de Díaz Ordaz la relación con Cuba fue más distante; al presidente le molestaba el apoyo que la isla daba a las guerrillas latinoamericanas $y$, al finalizar su sexenio, las relaciones casi llegaron a una debacle porque un funcionario de la embajada en La Habana espiaba para la CIA (Torres, 2010, pp. 191-192). Antes de esta crisis, a petición del secretario Rusk el gobierno mexicano hizo gestiones para que Fidel Castro permitiera la salida de los ciudadanos estadunidenses que quisieran hacerlo a través de México. El cubano aceptó y el ejecutivo mexicano ofreció dar visas a los estadunidenses que lo solicitaran. El grupo saldría de La Habana en un vuelo de Mexicana de Aviación y Castro pidió no se le diera mucha publicidad a este tema en Estados Unidos. ${ }^{19} 169$ personas dejaron Cuba mediante este arreglo orquestado por México en diciembre de 1966 y otras 71 lo hicieron el 5 de diciembre de $1967 .^{20}$

La información que se generaba en México era relevante dentro de la estrategia de seguridad nacional de Estados Unidos porque aquel mantenía relaciones con algunos disidentes de sus aliados en América Latina, con Cuba y otras naciones del bloque socialista. En esta línea, Díaz Ordaz le comentó a Freeman que el embajador en Moscú Carlos Zapata Vela le había transmitido el interés del embajador de Vietnam del Norte en que él recibiera a su homólogo que estaba en La Habana. El presidente aceptó recibirlo de forma extraoficial y confidencial y aseguró a Freeman que le informaría del contenido de estas conversaciones, aunque no era optimista respecto a su utilidad para Estados Unidos. ${ }^{21}$ El embajador visitó México y se reunió con el presidente en abril (Aguayo, 1998, p. 225).

Muestra de la estrecha colaboración entre ambos países, que en el ámbito público trataba de disimularse, fue la decisión impropia y rayana en la zalamería del canciller Carrillo Flores de compartir con el embajador Freeman el contenido de sus pláticas e impresiones de su viaje oficial a la URSS

${ }^{19}$ State Department, Memorandum of Conversation. 3 de diciembre de 1966, caja 59, fólder 6, 39b. LBJ, NSF, CFLAM.

${ }^{20}$ Attachment made oficially at $1 \mathrm{pm}$ today on the American citizens. 4 de diciembre de 1967, caja 60, fólder 1, 30. LBJ, NSF, CFLAM.

${ }^{21}$ Cable from the Embassy of the United States in Mexico to the Secretary of State. Febrero de 1968, caja 60, fólder 5, 26. LBJ, NSF, CFLAM.

\section{()ㅜ(1) $\$$}


en mayo de 1968. Se reunieron durante dos horas en las que Carrillo Flores le dio los pormenores del viaje y le leyó el informe que rindió al presidente Díaz Ordaz. Freeman consideró que muchas de las declaraciones de Andrei Gromyko, canciller de la URSS, no constituían novedades para ellos, como el supuesto interés de aquella república de no favorecer la exportación del modelo cubano en América Latina, y que las "confesiones" de Gromyko habían sido hechas con la intención de que llegaran a oídos de Washington. ${ }^{22}$ Llamaba la atención el deseo expresado por la URSS de que progresaran las pláticas de paz con Vietnam comenzadas en París en aquel año, cuando el gobierno de Johnson se vio orillado a iniciarlas ante la creciente oposición de la población estadunidense a que continuara la guerra, expresada en grandes manifestaciones en Nueva York, Washington y otras ciudades desde el año anterior. El número de soldados estadunidenses desplegados en Vietnam alcanzaba ya el medio millón para 1968 (Brinkley, 2003, pp. 963 y 968). ${ }^{23}$ Una de las afirmaciones del canciller, que parecieron muy interesantes a los analistas de seguridad en Washington, fue la lista de prioridades soviéticas de política exterior en el mundo. Llamó su atención especialmente el dicho de que en el remoto caso de una confrontación militar sino-soviética, Moscú buscaría una alianza con Estados Unidos. Pero el analista dudaba de que Gromyko hubiera dicho tal cosa y se la atribuía a Carrillo Flores, ${ }^{24}$ lo cual denota que Washington no estaba al tanto de la profunda confrontación sino-soviética.

En los informes de la cia se podía apreciar la confianza en la capacidad y eficiencia del gobierno mexicano para contener las diferentes manifestaciones de oposición, en la funcionalidad del PRI para dar salida al descontento social y en la válvula de escape que permitía que el radicalismo se expresara en la prensa y en otros foros porque servía al propio sistema. ${ }^{25}$ No obstante, esta confianza recibió un golpe cuando Rusk le preguntó al canciller mexicano en la Asamblea General de la onU, en septiembre de 1965, si necesitaba asistencia a propósito de una asonada que tuvo lugar en el norte del país hacía poco tiempo. Es muy posible que Rusk se refiriera al asalto al cuartel de Ciudad Madera, en Chihuahua, que realizó un grupo de trece

${ }^{22}$ Cable from Ambassador Freeman. 8 de junio de 1968, caja 60, fólder 5, 5a. LBJ, NSF, CFLAM.

${ }^{23}$ Paris Peace Talks. Public Broadcasting Service, People and Events. Recuperado de http://www.pbs.org/wgbh/amex/honor/peopleevents/e_paris.html

${ }^{24}$ Draft of cable to the Embassy in Mexico. s. f., caja 60, fólder 5, 4a . LBJ, NSF, CFLAM.

${ }^{25}$ Intelligence Memorandum. 13 de mayo de 1965, caja 2, fólder 6, 16. LBJ, NSF, CFLAM.

\section{()(1) $(3$}


combatientes radicales el 23 de septiembre de 1965. Rusk le preguntó a Carrillo Flores si estos hombres habían recibido entrenamiento en Cuba, a lo que respondió no saber. El estadunidense le recomendó que, aunque esto fuera un asunto aislado y pequeño, el gobierno debía tomar medidas para evitar que este tipo de problemas se diseminara. El canciller asintió y señaló que si México necesitaba entrenamiento para controlar a estos movimientos, se lo haría saber a Washington. ${ }^{26}$

Pese a este tropiezo, la ciA realizó una evaluación muy positiva sobre las condiciones de seguridad durante la visita del presidente Johnson a la ciudad de México en abril de 1966. Advertía que la situación del país no era equiparable a la de ninguna otra nación de América Latina por su fortaleza política y su sistema de seguridad. No sin un dejo de admiración anotaba el informe que algunas de las medidas tomadas por el gobierno, previo a la visita del mandatario, eran impensables en muchos países. Señalaba que habían sido detenidos 500 posibles alborotadores por la policía y que las autoridades se entrevistaron con 47 líderes de varias fuerzas políticas de izquierdas a quienes advirtieron que se les consideraría directamente responsables de cualquier manifestación antiestadunidense durante la visita. Que la policía secreta había allanado la imprenta del PCM y confiscado volantes con propaganda contra Estados Unidos, así como una pancarta que estaba preparando la Juventud Comunista. Fueron de tal eficiencia las medidas tomadas, advertía el informe, que los pequeños brotes antiestadunidenses pasaron desapercibidos para la mayoría gracias a la rápida actuación de la policía; que los estudiantes que tomaron Radio Universidad para transmitir consignas fueron sacados del aire en menos de un minuto y un hombre que intentó acercarse al automóvil donde viajaban los dos presidentes para gritar su oposición a la política estadunidense fue sacado de en medio con un garrote policiaco. ${ }^{27}$ Para la fecha en que Johnson realizó su visita a México, la cia consideraba que el Movimiento de Liberación Nacional, fundado en 1961, había perdido mucho del apoyo que tuvo en su origen y se había debilitado a causa de los desacuerdos entre sus líderes. ${ }^{28}$ La confianza de la CiA en la eficiencia de la policía para contener disturbios mostraría ser una quimera. Una vez que

${ }^{26}$ Memorandum of Conversation between Dean Rusk and Carrillo Flores. 30 de septiembre de 1965, caja 59, fólder 2, 109. LBJ, NSF, CFLAM.

${ }^{27}$ CIA. Office of National Estimates, Memorandum to the Director. 6 de mayo de 1966, caja 59, fólder 7, 96a. LBJ, NSF, CFLAM.

${ }^{28}$ CIA. Security Conditions in Mexico. 7 de abril de 1966, caja 59, fólder 8, 101. LBJ, NSF, CFLAM.

\section{()(1) $(9$}


inició el movimiento estudiantil de 1968 la policía mexicana mostró su incapacidad para lidiar con él (Rodríguez, 2003, p. 189).

\section{INICIA EL MOVIMIENTO ESTUDIANTIL DEL 68}

Esta movilización que inició a finales de julio y concluyó en octubre de 1968, luego que un baño de sangre en la Plaza de las Tres Culturas aterrorizó a los jóvenes y a quienes los apoyaban el 2 de octubre, generó un buen número de informes de parte de la embajada, el Departamento de Estado, la CIA, el FBI y los funcionarios emplazados en México por el Departamento de Defensa. Sin duda, fue un movimiento que causó preocupación en el gobierno estadunidense, como lo testimonia la documentación producida; no obstante, su visión sobre lo que sucedía en México no siempre coincidía con la de la administración mexicana, pese a que, como hemos señalado, ambas administraciones compartían un anticomunismo exacerbado.

Un interesante informe de la cia en Washington titulado "México: Los problemas del progreso", elaborado el 20 de octubre de 1967, realizó una atinada evaluación de los focos rojos del país. Algunas de sus conclusiones apuntaban al escenario en que se desarrollaría el mayor desafío al gobierno de Díaz Ordaz, así como la preocupación por el problema campesino en México. Este documento comenzaba:

El paisaje general de México es de progreso económico y estabilidad política, pero la inconformidad manifestada durante el año pasado apunta a dos problemas básicos [...] la pobreza [es] un problema creciente y serio. El segundo problema proviene del éxito del sistema educativo, que ha llevado a la clase media en expansión de las zonas urbanas más prósperas a un nivel de sofisticación que conducirá a un conflicto con el sistema paternalista del gobierno mexicano. Este grupo educado se está volviendo abiertamente crítico del espacio que separa al México real del México de la propaganda "revolucionaria" del gobierno. ${ }^{29}$

En la parte relativa a los antecedentes mencionaba sin ambages: "México retira a sus dictadores cada seis años." No obstante, advertía que el

${ }^{29}$ CIA. Directorate of Intelligence. Mexico The Problems of Progress, 20 de octubre de 1967, caja 60, fólder 1, 37. LBJ, NSF, CFLAM.

\section{(ㅇ)(1) $\$$}


avance en las comunicaciones y la educación había hecho que los campesinos estuvieran más conscientes y anhelaran un mejor nivel de vida. La preocupación de la ciA en este punto posiblemente se relacionaba con la presencia del movimiento guerrillero de Genaro Vázquez, que rondaba en Guerrero, y el inicio de la guerrilla de Lucio Cabañas, quien había huido a la sierra después de la matanza de Atoyac en 1967. Pese a todo, la agencia confiaba en que la paz sería mantenida por un ejército "brutalmente efectivo y astuto políticamente. El ejército ha despachado unidades a zonas de agitación publicitando maniobras de entrenamiento; han usado las laderas de las montañas para prácticas masivas de tiro, haciendo volar en pedazos todos los objetos." ${ }^{30} \mathrm{El}$ problema del campo era vislumbrado como un asunto muy complejo pues el gobierno no podría repartir tierras de "pequeños propietarios" sin dañar la producción agrícola.

Sobre el crecimiento de una clase media educada y con una situación económica desahogada, el desafío provenía de este sector que ya no creía en la propaganda oficial, resentido con las políticas oficiales a las que calificaba como "cínicas". Un ejemplo de ello lo constituyen las expresiones ciudadanas en contra del "dedazo", tal como se manifestaron en Sonora entre febrero y mayo de 1967. Aunque el presidente había realizado intentos por abrir el sistema político, de acuerdo con la visión del reseñista de la CIA, estas medidas habían provocado antagonismos y aumentado las tensiones en el partido. Aún no llegaba el día en el que el PRI, como un organismo unido, pudiera dar pasos hacia la democratización. ${ }^{31}$

Pese a los focos rojos que el informe señalaba, la cia y el gobierno estadunidense confiaban en la estabilidad mexicana y en la capacidad de las fuerzas de seguridad para mantener el control de los movimientos opositores. Esta confianza se relacionaba con el papel preponderante que México desempeñaba como aliado regional, dadas las preocupaciones de Washington de contener a Cuba, lograr que disminuyeran las actividades revolucionarias y reducir el sentimiento antiestadunidense en el continente. Esta certidumbre explica las relativamente bajas exportaciones de equipo militar y de con-

${ }^{30}$ CIA. Directorate of Intelligence. Mexico The Problems of Progress, 20 de octubre de 1967, caja 60, fólder 1, 37. LBJ, NSF, CFLAM.

${ }^{31}$ CIA. Directorate of Intelligence. Mexico The Problems of Progress, 20 de octubre de 1967, caja 60, fólder 1, 37. LBJ, NSF, CFLAM. Las reformas que intentó aplicar Carlos A. Madrazo como presidente del PRI para democratizar al partido fracasaron. Díaz Ordaz no las impulsó ni le dio su apoyo a Madrazo, quien en 1965 salió del partido (Hernández, 2000, p. 292).

\section{()(1) $\$$}


tención policiaca y el bajo número de militares y policías que recibían entrenamiento en Estados Unidos, en comparación con Latinoamérica, durante la mayor parte de la década de los sesenta (Zolov, 2003, pp. 43-44).

Previo al inicio del movimiento estudiantil, la embajada realizó una evaluación sobre la posibilidad de que en México detonara una movilización similar a la que ocurría en Francia y, a diferencia de la cia, no veía los focos rojos que el informe de la agencia había señalado unos meses antes sobre la posibilidad de que entre los jóvenes de clase media surgiera inconformidad. Decía que el PRI y el gobierno controlaban a la opinión pública y eran sensibles a las demandas populares, en tanto que la oposición de izquierda era muy débil y carecía de recursos. Creía que, pese a los problemas del país, como el crecimiento de la población, el desempleo, la expansión de las áreas urbanas pobres y la escasez de tierra, era poco probable que estallaran conflictos durante la administración de Díaz Ordaz. Aunque reconocía que la inconformidad estudiantil podía surgir en cualquier momento y con cualquier pretexto, pensaba que el gobierno era capaz de terminar con ella y ofrecer salidas aceptables. En lo que sí atinó en su proyección a futuro fue en considerar que una movilización estudiantil por sí sola no podría expandirse a nivel nacional, ni poner en serio peligro a la administración a menos que tuviera apoyo de otros sectores como los trabajadores, los pobres urbanos o los campesinos, situación poco probable, pues en general estos habían sido apáticos e incluso contrarios a los "desórdenes estudiantiles" que estallaron con anterioridad. En disonancia con el informe de la ciA de octubre de 1967, el embajador creía que el gobierno manejaba el liderato de los trabajadores y los campesinos y, de una forma menos disciplinada, el de los profesionistas, comerciantes y burócratas, de manera que era improbable que dicho liderazgo se volcara contra el gobierno como había sucedido en Francia. ${ }^{32}$

La embajada realizó un análisis de la situación de la juventud, complementario al anterior, el 6 de julio, en el cual no veía ningún peligro de descontento, confiaba en la capacidad del gobierno para someter a los estudiantes en caso de conflictos, como había sucedido por la vía de la negociación en Durango en 1966 y en Tabasco en 1968, o enviando tropas a ocupar las universidades como se hizo en Morelia en 1966 y en Hermosillo en 1967. Consi-

32 Telegrama confidencial de la embajada al Departamento de Estado. 14 de junio de 1968. The National Security Archive. The George Washington University, The Mexico Project, Tlatelolco Masacre Declasified US Documents on Mexico on the Events of 1968 (en adelante NSA, MP, TTMUSD). Washington D. C. Recuperado de http://nsarchive.gwu.edu/ NSAEBB/NSAEBB99/Doc1.pdf

\section{()(1) $(9$}


deraba que los estudiantes universitarios, si bien mantenían actitudes antiimperialistas y antiestadunidenses, se movilizaban muy poco en contra de Vietnam o de la invasión a República Dominicana, y una vez que se convertían en profesionistas dejaban atrás el radicalismo juvenil. Los estudiantes consideraban que existían oportunidades de mejoramiento social en el país, en tanto que las juventudes de pobres rurales o urbanos se casaban más jóvenes, por lo que sus preocupaciones no estaban en la política, sino en fundar una familia y sostenerla. Así, pese a que $71.7 \%$ de la población era menor a 35 años en México, la juventud no era un reto al gobierno, según este informe. ${ }^{33}$

No obstante, a medida que se acercaba la fecha de la inauguración de los XIX Juegos Olímpicos creció la inquietud entre el gobierno mexicano por que pudiera surgir un movimiento estudiantil que intentara boicotear los juegos. Esta preocupación pronto contagió a la CIA, la cual, debido a la estrecha colaboración con los aparatos de seguridad mexicanos, perdía objetividad en sus apreciaciones y repetía información sin confirmarla de manera independiente. ${ }^{34}$ Así, en su informe del 19 de julio se refirió a las movilizaciones estudiantiles en Puebla y en Veracruz, y en este último estado, aseguraba, había infiltración cubana; señalaba además la posibilidad de que algunos "agitadores" pudieran desatar disturbios en la Universidad Nacional Autónoma de México (UNAM) durante los juegos que iniciarían en octubre de $1968 .{ }^{35}$ Díaz Ordaz, preocupado por la estabilidad y el avance de la guerrilla en Latinoamérica, confió a Luis M. Farías, un político cercano, que con motivo de las olimpiadas: "El mundo estará pendiente de nosotros y quién sabe qué maldad nos tenga preparada" (Loaeza, 2005, p. 147).

Una vez que inició el movimiento, el 26 de julio, es posible que el presidente haya dado crédito a los numerosos informes de la Dirección General de Investigaciones Políticas y Sociales (DGIPs) de la Secretaría de Gobernación sobre la presencia de agitadores comunistas provenientes de Cuba y de países del bloque socialista que, mediante una conjura orquestada, dieron inicio a la movilización (Keller, 2015, p. 202). Los informes del embajador, en cambio, atribuyeron los hechos a agitadores profesionales provenientes del

${ }^{33}$ U S Embassy in Mexico. Confidential Cable to the Department of State. 6 de julio de 1968. NSA, MP, TTMUSD. Recuperado de http://nsarchive.gwu.edu/NSAEBB/NSAEBB99/ Doc2.pdf

${ }^{34}$ Sobre este punto se puede ver Litempo: The CIA's Eyes on Tlatelolco. NSA, MP, L. Recuperado de http://nsarchive.gwu.edu/NSAEBB/NSAEBB204/index.htm

35 CIA. Weekly Summary, Student Unrest Trouble Mexico. 19 de julio de 1968. NSA, MP, TMDUSD. Recuperado de http://nsarchive.gwu.edu/NSAEBB/NSAEBB10/docs/doc01.pdf

\section{()(1) $(2$}


PCM, quienes obraron siguiendo los mandatos de Moscú a través de su embajada en México. Freeman informó que habían sido aprehendidos entre 62 y 78 "agitadores", muchos de ellos miembros del PCM, y que entre ellos había dos detenidos estadunidenses. ${ }^{36}$ La estación local de la ciA responsabilizaba de los desórdenes a comunistas mexicanos y desmentía la participación de la URSS. Le parecía improbable que la embajada, cuyos teléfonos estaban intervenidos por la ciA (Morley, 2010, pp. 133-134), pusiera en riesgo sus cuidadosamente cultivadas relaciones con México. ${ }^{37}$ Por su parte, los expertos del Departamento de Estado apuntaban al hecho de que los informes de la embajada no aportaban información independiente que confirmara la participación soviética, ${ }^{38}$ mientras que el subsecretario de Estado para Asuntos Latinoamericanos era escéptico respecto a la participación de comunistas y apuntaba más bien a que el gobierno había aprovechado los disturbios para encarcelar a algunos comunistas que podrían generar conflictos durante las olimpiadas. ${ }^{39}$ En estos primeros informes se pueden apreciar contradicciones: el gobierno mexicano y el embajador estadunidense, contaminado por las declaraciones de las autoridades y la prensa nacional, creían que efectivamente el conflicto se había desatado por la injerencia de los "agitadores" de origen cubano o del bloque soviético, o por miembros del PCM que seguían los dictados de la URSS. En cambio, la ciA local y el Departamento de Estado no creían en esta versión. La primera seguramente contaba con información dura al respecto, en tanto que el Departamento de Estado -quien tenía un conocimiento más profundo sobre México que la embajada o incluso la pro-

${ }^{36}$ US Embassy. Telegram. 28 de julio de 1968. NSA, MP, TTMUSD. Recuperado de http:// nsarchive.gwu.edu/NSAEBB/NSAEBB99/Doc4.pdf. Telegram from Freeman to the State Department. 30 de julio de 1968, caja 60, fólder 6, f. 48 ${ }^{\mathrm{a}}$. LBJ, NSF, CFLAM. Novedades reportaba que los detenidos eran 76 "agitadores comunistas", y, según palabras del jefe de la policía Luis Cueto Ramírez, "actua[ban] a fin de crear un ambiente negativo para México durante los juegos olímpicos". "76 agitadores rojos que integraron los disturbios estudiantiles están detenidos”, Novedades, 28 de julio de 1968 (Cano, 1998, p. 12). Los integrantes del MURo, grupo de jóvenes católicos de ultraderecha, tildaron a las personas que protestaban de "jóvenes marxistas" que persiguen "entregar nuestra patria al marxismo internacional". "Fija su posición el MURo", El Universal, 28 de julio de 1968 (Cano, 1998, p. 12).

${ }^{37}$ Resumen de la CiA en México. 2 de agosto de 1968. NSA, MP TTMUSD. Recuperado de http://nsarchive.gwu.edu/NSAEBB/NSAEBB99/Doc53.pdf

${ }_{38}$ Memorandum to Johnson from William Bowdler. Student Disturbances in Mexico City. 31 de julio de 1968. NSA, MP TTMUSD. Recuperado de http://nsarchive.gwu.edu/NSAEBB/NSAEBB10/docs/doc02.pdf

${ }^{39}$ Information Memorandum from the Assistant Secretary of State for Inter-American Affairs (Oliver) to Secretary of State Rusk, Washington. 31 de julio de 1968. DS, OH, SCAM. Recuperado de http://history.state.gov/historicaldocuments/frus1964-68v31/d362

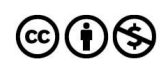


pia ciA local- atribuyó la versión del gobierno a la costumbre de Díaz Ordaz de culpar a instigadores externos de los movimientos opositores nacionales.

En cuanto al ingreso del ejército a la Preparatoria 1, en el centro de la ciudad, en la madrugada del 30 de julio -que voló la puerta de la escuela con una bazuca y desalojó a los estudiantes-, el Departamento de Inteligencia Militar de la embajada informó que el ejército actuó con exceso de rudeza. ${ }^{40}$ De acuerdo con informes policiales, resultaron cuatro muertos y unos 200 heridos como saldo de la represión, información que, de conocerse, según el Departamento de Estado, podría desatar protestas ${ }^{41}$ La decisión del gobierno de involucrar al ejército en la represión de los jóvenes que se atrincheraron en la Preparatoria surgió luego de que los granaderos casi fueron rebasados por la resistencia de los amotinados (Rodríguez, 2003, p. 191). Con la intervención militar en instalaciones de la UNAM, escaló el movimiento y muchos profesores de enseñanza profesional se unieron a él.

Por su parte, el director de Inteligencia del Departamento de Estado hacía su propia evaluación, la cual, tal vez por la lejanía, resulta más certera. Consideraba que al acercarse la fecha de las olimpiadas las fuerzas de seguridad aumentarían su sensibilidad hacia cualquier problema y el gobierno actuaría con mayor fuerza para descabezar al movimiento, y que, no obstante que este no representaba una amenaza real contra la administración, aquel no olvidaría fácilmente el desprestigio internacional que le había causado. Afirmaba que ya estaban presos los "agitadores estudiantiles" y que serían deportados cinco estudiantes franceses que participaron en las actividades de finales de julio. Sobre la participación de los comunistas consideraba que el gobierno insistiría en que ellos orquestaban las movilizaciones "en un intento por disminuir la importancia de la participación de no comunistas". ${ }^{2}$ Con ello evidenciaba que creía que existían razones internas que explicaban el conflicto y no se trataba de una conjura instigada por un pequeño grupo, como insistían las versiones oficiales y los propios grupos anticomunistas nacionales.

${ }^{40}$ Informe del Departamento de Inteligencia militar. [s. f.]. NSA, MP, TTMUSD. Recuperado de http://nsarchive.gwu.edu/NSAEBB/NSAEBB10/docs/doc04.pdf

${ }^{41}$ Information Memorandum From the Assistant Secretary of State for Inter-American Affairs (Oliver) to Secretary of State Rusk, Washington. 31 de julio de 1968. DS, OH, sCAM. Recuperado de http://history.state.gov/historicaldocuments/frus1964-68v31/d362

${ }^{42}$ Nota del director de Inteligencia e Investigación del Departamento de Estado. 6 de agosto de 1968. NSA, MP, TTMUSD. Recuperado de http://nsarchive.gwu.edu/NSAEBB/ NSAEBB99/Doc29.pdf

\section{()(1) $(9$}


Hacia finales de agosto la embajada hizo una evaluación que consideró la influencia de los movimientos estudiantiles de Francia, Japón, Estados Unidos y Checoeslovaquia en el mexicano y admitió, a diferencia de sus informes anteriores, que no era posible confirmar la participación de los comunistas extranjeros. Asimismo, señaló que ninguna movilización estudiantil anterior había provocado tales niveles de violencia contra los estudiantes, ni tal animadversión de estos en contra del gobierno. Consideraba que en el transcurso de agosto el gobierno no había intervenido en las marchas a la espera de que la cercanía de las vacaciones desinflara la participación de los jóvenes, aunque sus agentes seguían tratando de dividir y debilitar el liderazgo de los dirigentes más radicales del Consejo Nacional de Huelga $(\mathrm{CNH}) .{ }^{43}$ En este informe la embajada se alejaba de la visión oficial de la conjura internacional sostenida por las autoridades. Para ese entonces, la prensa liberal estadunidense ya veía con simpatía al movimiento (Zolov, 2003, p. 51), en tanto que su contraparte mexicana, totalmente controlada por el Estado, repetía la versión oficial.

La manifestación del 27 de agosto, una de las más numerosas, ${ }^{44} \mathrm{culmi}$ nó con la permanencia de un grupo de estudiantes en el Zócalo que pidieron que el diálogo público con el gobierno, una de sus demandas, se diera el 1 de septiembre, la fecha del informe presidencial. Propusieron que en tanto este llegaba, un grupo de estudiantes custodiara el lugar. Cuando la manifestación llegó a la plaza, un grupo de estudiantes de medicina entró a la catedral $y$, con permiso de las autoridades, encendieron las luces y tocaron las campanas. El informe de la embajada advirtió que la crítica estudiantil contra el gobierno había subido de tono, como lo mostraban las pancartas "irrespetuosas" al presidente durante la marcha de alrededor de 100000 jóvenes, y reportó el aumento de la represión. Durante la madrugada las tropas desalojaron con tanques a los jóvenes que permanecían en la plaza. A la mañana siguiente el gobierno organizó un acto de desagravio a la bandera porque un grupo de jóvenes había izado una bandera rojinegra en el asta del Zócalo durante la víspera. A este acto llevaron a empleados acarreados del Departamento del Distrito Federal, quienes al comenzar a gritar consignas contra el gobierno

${ }^{43}$ Informe de la embajada sobre los disturbios estudiantiles en México en años recientes. 23 de agosto de 1968. NSA, MP, TTMUSD. Recuperado de http://nsarchive.gwu.edu/ NSAEBB/NSAEBB99/Doc9.pdf. Telegrama de la Embajada de México. Desórdenes estudiantiles. 27 de agosto de 1968. NSA, MP, TTMUSD. Recuperado de http://nsarchive.gwu.edu/ NSAEBB/NSAEBB99/Doc10.pdf

${ }^{44}$ Algunos calculan en alrededor de 400000 los asistentes a ella, otros hablan de 200000 .

\section{()(1) $\$$}


fueron sacados de la plaza por el ejército junto con los estudiantes que habían llegado. Este desalojo se caracterizó por la violencia desatada. ${ }^{45}$ La Oficina de Inteligencia e Investigación del Departamento de Estado apuntó que con lo sucedido había terminado la tolerancia del gobierno, quien optó por el uso de la fuerza, exacerbando las diferencias entre ambos bandos y poniendo fin a la posibilidad de llegar a algún arreglo. ${ }^{46}$

Walter Rostow, consejero de Seguridad Nacional del presidente Johnson, le remitió un informe confidencial sobre la situación en México. Advertía que las autoridades habían dejado que los estudiantes realizaran manifestaciones libremente pensando que el movimiento se desinflaría, pero la estrategia no había funcionado y los disturbios habían escalado, en referencia al desalojo del Zócalo, a la proliferación de los mítines relámpago y a las brigadas de distribución de propaganda en la ciudad. Así, Díaz Ordaz endureció su postura y ordenó al ejército y la policía que disolvieran las actividades y reuniones "ilegales". Grupos de campesinos se habían unido a los estudiantes, señalaba el informe, "añadiendo una amenazadora nueva dimensión a la situación". Consideraba que por el momento la violencia no era un peligro a la estabilidad del gobierno, pero que podría afectar seriamente la atmósfera preolímpica, lo que seguramente había llevado al presidente a cambiar de táctica. ${ }^{47}$ Rostow anexó un cable, procedente de la embajada en México, que informaba que durante los choques en el Zócalo habían resultado heridos seriamente varios manifestantes. ${ }^{48}$ Para entonces, intelectuales y académicos se habían unido a la lucha estudiantil; el CNH había elaborado un pliego petitorio de seis puntos que apuntaba al desmantelamiento del aparato represor del régimen (Álvarez, 1998, pp. 54-64), al tiempo que con sus actividades desnudaba al autoritarismo.

La violencia que se vivió el 27 y 28 de agosto ha tenido diferentes interpretaciones. Para Gilberto Guevara Niebla (2004, pp. 224-225) lo sucedido demuestra la presencia de provocadores pagados por el gobierno para debilitar al movimiento, entre ellos Sócrates Amado Campos Lemus, quien radi-

45 Telegrama confidencial de la Embajada de México. 30 de agosto de 1968. NSA, MP, TTMUSD. Recuperado de http://nsarchive.gwu.edu/NSAEBB/NSAEBB99/Doc12.pdf

${ }^{46}$ Oficina de Inteligencia e Investigación. Departamento de Estado. Nota confidencial. 29 de agosto de 1968. NSA, MP, TTMUSD. Recuperado de http://nsarchive.gwu.edu/NSAEBB/ NSAEBB99/Doc32.pdf

${ }^{47}$ Confidential Report from Rostow to Johnson. 29 de agosto de 1968, caja 60, fólder 6, 42 d. LBJ, NSF, CFLAM.

${ }^{48}$ Telegram from Embassy of Mexico to State Department [s. f.], caja 60, fólder 6, $42 \mathrm{f}$. LBJ, NSF, CFLAM.

\section{()(1) $(9$}


calizó con su discurso a los asistentes al mitin que se organizó en el Zócalo luego de la manifestación. Raúl Álvarez Garín (1998, p. 61) considera que fue un error táctico mantener a un grupo de estudiantes en la plaza mientras llegaba el 1 de septiembre. Jaime Pensado sostiene que estos hechos evidencian la radicalización del movimiento y el ascenso de anarquistas (Pensado, 2013, p. 208). ${ }^{49}$ Guevara Niebla dijo también durante una entrevista que la CIA infiltró el movimiento con objeto de poner en marcha una "represión preventiva", y que quienes la echaron a andar estaban vinculados al menos indirectamente con la agencia. A pesar de ello, más adelante señaló que los provocadores tal vez no pertenecían a la cia sino a la Dirección Federal de Seguridad (DFS). ${ }^{50}$ Dadas las múltiples actividades de contrainsurgencia que montó la ciA en América Latina durante la guerra fría, se explica que algunos actores de izquierdas hayan pensado que esta agencia infiltró al movimiento estudiantil mexicano. No obstante, estas afirmaciones carecen hasta ahora de sustento documental. ${ }^{51}$ Es posible que algunos agentes de la DFs lo fueran también de la ciA, pero ello no demuestra que esta haya sido corresponsable de la represión que se desató.

Hacia finales de agosto el gobierno realizaba toda clase de intentos para poner fin a la movilización. La Secretaría de Gobernación publicó un anuncio en la prensa invitando al diálogo a los estudiantes, quienes deberían comunicarse por teléfono (Álvarez, 1998, p. 58). Pero el CNH rechazó la propuesta creyendo que si iniciaban los contactos se desinflaría la participación (Hodges y Gandy, 2002, p. 97). Así, cuando llegó la manifestación del 27 de agosto, la línea dura parecía haber ganado el control del movimiento y el gobierno aumentó la represión ante la urgencia de liquidar el conflicto debido a la cercanía de las olimpiadas. Tanto el Departamento de Estado, como la embajada y Rostow coincidían en que la cercanía de los juegos había terminado con la tolerancia del ejecutivo. A partir de entonces, en Washington aumen-

${ }^{49}$ La bandera rojinegra no demuestra la presencia de anarquistas, como supone Pensado. En México esta bandera es la de huelga y por ello el $\mathrm{CNH}$ la usaba. Además, este autor menciona que los grupos de estudiantes que penetraron en la catedral y tocaron las campanas, colocaron un retrato del Che Guevara sobre uno de los altares, atribuyendo estos hechos a grupos radicales, pero no cita la fuente de esta información que no figura en la prensa de la época, adversa casi totalmente al movimiento.

50 "Delación y colaboracionismo, estigmas de Sócrates Amado Campos Lemus", La Jornada, 26 de abril de 2004. Recuperado de http://www.jornada.unam.mx/2004/04/26/007n1pol. php?origen=politica. php\&fly $=2$

${ }_{51}$ El material disponible hasta el presente no aporta pruebas en ese sentido. Por su parte, Aguayo (1998) también desmiente la participación de la ciA en el movimiento.

\section{()(1) $\$$}


taron las menciones de México por parte de la cia que, en los resúmenes diarios que entregaba al presidente para que estuviera al tanto de los asuntos de seguridad que la oficina quería que conociera, reportó casi cotidianamente lo relacionado con el movimiento estudiantil. ${ }^{52}$

\section{LOS RELÁMPAGOS DE SEPTIEMBRE}

El presidente Díaz Ordaz presentó su informe al Congreso el 1 de septiembre de 1968, en él se refirió al conflicto estudiantil. Trató de vincular el movimiento con fuerzas externas e internas que amenazaban la tranquilidad del país y advirtió que llegarían hasta donde fuese necesario. ${ }^{53}$

Como se ha visto, desde finales de agosto los servicios de inteligencia estadunidenses habían notado una escalada en la represión, que se agudizó al mes siguiente. La interpretación del informe presidencial para la CIA era clara: las manifestaciones serían enfrentadas con medidas muy duras. ${ }^{54}$ El propio embajador Freeman coincidía al afirmar que había terminado el periodo de tolerancia y que ahora el gobierno estaba listo para iniciar la disolución del movimiento en vista del fracaso de su política anterior y de la cercanía de las olimpiadas. Al mismo tiempo, señalaba que el informe presidencial había sido una mezcla de condescendencia y amenaza. ${ }^{55}$

Por su parte, la estación de la cia en la ciudad de México realizó un balance de los acontecimientos y del informe. Anotaba que los estudiantes habían advertido su capacidad de influir en ciertos asuntos nacionales y señalaba que el $\mathrm{CNH}$, integrado por unos 140 estudiantes de la UNAM y el Instituto Politécnico Nacional (IPN), contaba con la asesoría de varios profesores, intelectuales de izquierdas conocidos. Añadía que el gobierno había

52 La CIA reportó el 31 de agosto que los estudiantes se preparaban con cocteles molotov para defender la UNAM, que el presidente estaba decidido a responder con firmeza a los rebeldes y que una pequeña bomba había estallado en la residencia de Freeman sin provocar daños. CIA, The President's Daily Brief (en adelante CIA, PDB), 31 de agosto de 1968. Recuperado de https://www.cia.gov/library/readingroom/docs/DOC_0005976333.pdf

${ }^{53}$ Cuarto informe de gobierno del presidente Gustavo Díaz Ordaz. Informes presidenciales. Gustavo Díaz Ordaz. Dirección servicios de investigación y análisis. Cámara de Diputados. LX Legislatura. Recuperado de http://www.diputados.gob.mx/sedia/sia/re/REISS-09-06-13.pdf

${ }^{54}$ Informe semanal de la CIA. 6 de septiembre de 1968. NSA, MP, TTMUSD. Recuperado de http://nsarchive.gwu.edu/NSAEBB/NSAEBB10/docs/doc08.pdf

${ }_{55}$ Telegrama del embajador Freeman. 6 de septiembre de 1968. NSA, MP, TTMUSD. Recuperado de http://nsarchive.gwu.edu/NSAEBB/NSAEBB99/Doc13.pdf

\section{(ㄷ)(1) $(3$}


esparcido rumores de que la cia había promovido el conflicto y no había perdido la oportunidad de culpar a los comunistas. El informe apuntaba que el presidente atribuía lo sucedido a agitadores soviéticos y cubanos y que el mismo era la fuente de esos rumores, pero la agencia aseguraba que no tenía evidencia que apoyara tal supuesto, y ponía en duda que Díaz Ordaz creyera esta versión. ${ }^{56}$ Es un hecho que los informes de las oficinas de seguridad mexicanas alimentaban la hipótesis del presidente (Aguayo, 2001, p. 133), preocupado porque la agitación interfiriera con los juegos olímpicos. El reporte de la CIA concluía afirmando que el PRI y el gobierno habían perdido la capacidad de controlar el comportamiento popular, que el conflicto estaba influido levemente por las rebeliones estudiantiles en Estados Unidos y Europa y que los disturbios constituían una nueva experiencia para México y podían ser una señal de las cosas por venir. ${ }^{57}$

Por su lado, los estudiantes realizaron una enorme manifestación silenciosa el 13 de septiembre para mostrar que no eran vándalos, portando carteles con héroes nacionales y banderas tricolores para expresar su nacionalismo. A la exigencia de diálogo público del $\mathrm{CNH}$ y a su apremio a que se realizase antes de las olimpiadas, la Secretaría de Gobernación respondió, como si se tratara de una amenaza, "la firme resolución de hacer uso de los recursos legales para que puedan efectuarse normalmente los Juegos". ${ }^{58} \mathrm{El}$ 18 de septiembre, el ejército ocupó la Ciudad Universitaria (cu) de la UNAM y el 24 lo hizo con las instalaciones del IPN en el Casco de Santo Tomás y Zacatenco en la ciudad de México. La embajada reportó que el secretario de Gobernación le había comentado que el liderazgo estudiantil no quería que se resolviese el conflicto y que el gobierno confiaba en que la aprehensión de los principales líderes estudiantiles antes de las olimpiadas garantizaría la realización de los juegos. Freeman señalaba que el aumento de la represión y el uso de armas de fuego para someter a los estudiantes habían desinflado la participación de los moderados en los eventos de septiembre y consideraba que la lucha estudiantil no era una verdadera amenaza a la olimpiada. ${ }^{59}$

${ }^{56}$ CIA, Intelligence Information Cable. 9 de septiembre de 1968, caja 60, fólder 6, 42. LBJ, NSF, CFLAM.

${ }^{57}$ CIA, Intelligence Information Cable. 9 de septiembre de 1968, caja 60, fólder 6, 42. LBJ, NSF, CFLAM.

58 "Nadie podrá impedir que se realice la Olimpiada", El Heraldo, 18 de septiembre de 1968 (Cano, 1998, p. 175).

59 Telegrama confidencial de la embajada. 26 de septiembre de 1968. NSA, MP, TTMUSD. Recuperado de http://nsarchive.gwu.edu/NSAEBB/NSAEBB99/Doc15.pdf. Telegrama se-

\section{()요 $\circledast$}


El análisis sobre la actuación de Díaz Ordaz que el subsecretario adjunto para Asuntos Interamericanos envió al secretario de Estado Rusk no era muy positivo; hablaba del endurecimiento de la represión y se refería a la toma de cu por el ejército y a la posibilidad de que fueran ocupadas otras instalaciones educativas. Mencionaba el desprestigio del presidente por las drásticas medidas tomadas y por su incapacidad para resolver el conflicto, añadiendo que los juegos olímpicos se celebrarían, y que aunque tal vez hubiera brotes aislados de violencia, los estudiantes, consideraba, no tenían apoyo sustantivo de la población y no podrían interrumpirlos. ${ }^{60}$

Visto en retrospectiva, llama la atención que los aparatos de seguridad estadunidenses sí advirtiesen el recrudecimiento de la represión desde finales de agosto, ${ }^{61}$ en tanto que los líderes del movimiento al parecer no la vieron venir (Álvarez, 1998, p. 71). La Oficina de Inteligencia e Investigación del Departamento de Estado descartaba que pudieran llegar a un acuerdo el gobierno y los estudiantes y añadía: "el uso de la fuerza para acabar con los disturbios triunfará en el largo plazo, pero generará una gran amargura entre los estudiantes y la administración". ${ }^{62}$ Por su parte, la estación de la CIA coincidía en las apreciaciones de sus colegas y señalaba los rumores que apuntaban a que algunos ex funcionarios estaban interfiriendo en razón de la lucha por la candidatura presidencial que se avecinaba, y que el gobierno utilizaría toda la fuerza para impedir que las escuelas fueran usadas como centros de actividad subversiva. ${ }^{63}$

Después de la manifestación del 13 de septiembre las refriegas entre jóvenes, policías y militares en diferentes partes de la ciudad proliferaron y la represión se tornó más violenta. En la Unidad Habitacional Santiago Tla-

creto de la embajada. 27 de septiembre de 1968. NSA, MP, TTMUSD. Recuperado de http:// nsarchive.gwu.edu/NSAEBB/NSAEBB99/Doc16.pdf

${ }^{60}$ Information Memorandum from the Assistant Secretary of State for Inter-American Affairs (Oliver) to Secretary of State Rusk. Washington. 20 de septiembre de 1968. Ds, OH, SCAM. Recuperado de http://history.state.gov/historicaldocuments/frus1964-68v31/d363

${ }^{61}$ El Departamento de Inteligencia Militar reportaba que la toma de cu significaba una nueva etapa de endurecimiento y que la participación de tropas venidas de fuera de la ciudad de México indicaba la seriedad que estaba tomando el asunto. Informe del Departamento de Inteligencia Militar. 24 de septiembre de 1968. NSA, MP, TMDUSD. Recuperado de http:// nsarchive.gwu.edu/NSAEBB/NSAEBB10/docs/doc12.pdf

${ }^{62}$ Nota confidencial de inteligencia. Oficina de Inteligencia e Investigación al Secretario de Estado. 26 de septiembre de 1968. NSA, MP, TTMUSD. Recuperado de http://nsarchive. gwu.edu/NSAEBB/NSAEBB99/Doc35.pdf

${ }^{63}$ Reporte de la CIA. 27 de septiembre de 1968. NSA, MP, TTMUSD. Recuperado de http:// nsarchive.gwu.edu/NSAEBB/NSAEBB99/Doc71.pdf

\section{(이요}


telolco se dio un enfrentamiento con la policía en el que los jóvenes tiraron bombas molotov, quemaron trolebuses y patrullas y contaron con el apoyo de algunos vecinos, quienes desde sus departamentos arrojaron objetos contra los granaderos. Durante esta confrontación se usaron armas de fuego contra los jóvenes, y algunos de ellos, y presumiblemente algunos vecinos, usaron también pistolas para repeler a los policías. En respuesta a la virulencia del ataque de los jóvenes apoyados por vecinos, la Escuela Vocacional 7 del IPN, ubicada en la Plaza de las Tres Culturas en Tlatelolco, fue ocupada por la tropa. ${ }^{64} \mathrm{El}$ resumen diario rendido por la CIA al presidente aseguraba que unas 1500 personas habían sido detenidas en los "sangrientos" disturbios y que el movimiento se estaba extendiendo a otras ciudades del país, sin que el ejecutivo mexicano diera muestras de poder terminar con el conflicto antes de los juegos olímpicos. ${ }^{65}$ Rusk solicitó al embajador que a partir de esa fecha informara diariamente su análisis sobre el movimiento (Aguayo, 1998, p. 179).

Un balance de lo sucedido en septiembre nos habla de cierta molestia de los aparatos de seguridad del país vecino por la incapacidad del gobierno de resolver el conflicto por medios pacíficos. Veían el incremento de la represión como un precio muy alto que la administración estaba pagando por su incompetencia, al tiempo que comprobaban que no existía la amenaza comunista interna o externa a la que Díaz Ordaz apelaba. Lo cierto es que, independientemente de sus críticas, el gobierno estadunidense apoyaba al mexicano para que saliera adelante de este difícil escollo. Prueba de ello son los suministros, el equipo antimotines y las armas que Washington vendió a México durante el verano de aquel año; material que tenía como finalidad principal enfrentar al movimiento estudiantil (Witherspoon, 2008, p. 156). A medida que se acercaba el 12 de octubre, fecha de la inauguración de los juegos olímpicos, el gobierno mexicano se inclinaba peligrosamente por una salida de fuerza.

\section{¿POR QUÉ?}

Con un rectángulo negro y la leyenda “Por qué?” Abel Quezada publicó su caricatura en Excélsior para fijar su postura frente a la masacre sucedida en la

64 "Barrió el ejército con un foco de subversión en Tlatelolco", El Sol de México, 22 de septiembre de 1968 (Cano, 1998, p. 201).

${ }_{65}$ The President's Daily Brief. 13 de septiembre de 1968 (CIA, PDB), Recuperado de https://www.cia.gov/library/readingroom/docs/DOC_0005976371.pdf

\section{(ㅇ)(1) $\$$}


Plaza de las Tres Culturas la tarde del 2 de octubre. La versión oficial del gobierno fue que los estudiantes colocaron francotiradores e iniciaron la balacera como una provocación contra el ejército. ${ }^{66}$ Esta interpretación coincidía con la percepción de los aparatos de seguridad estadunidenses asentados en la ciudad de México al señalar que los estudiantes desplegaron francotiradores con armas automáticas que dispararon indiscriminadamente contra el ejército y la gente que concurría al mitin que comenzó a las 5 de la tarde. ${ }^{67}$ No era casual la coincidencia, los funcionarios replicaron la información que recibieron del gobierno y su aparato de seguridad y que reproducía la prensa, en una época en la que no existía libertad de expresión en México.

De inmediato, el subsecretario de Estado para Asuntos Latinoamericanos, Covey T. Oliver, envió un memorándum a su jefe. Decía que lo sucedido la noche anterior había sido una "provocación de estudiantes extremistas y una brutal sobre reacción de las fuerzas de seguridad. Fue un duro golpe al presidente y su gobierno, tanto por el uso excesivo de la fuerza como porque subraya el fracaso del GoM [Gobierno de México] después de once semanas, de evitar la violencia." Añadía que no era necesario dar aviso de que era peligroso visitar la ciudad de México porque la violencia afectó sólo a ciertas áreas de la ciudad. Por su parte, las agencias de seguridad realizaron evaluaciones que se centraron en la participación de cubanos y soviéticos en los acontecimientos y en dilucidar la responsabilidad de quienes habían iniciado los disparos en la plaza. La ciA en Washington aseveraba que no había evidencia de que agentes soviéticos y cubanos hubieran orquestado los disturbios, la embajada de Cuba en México, señalaba, había apoyado a los estudiantes con unos miles de pesos para propaganda al inicio del movimiento. Reconocía la participación del PCM, de trotskistas y castristas en la lucha, pero concluía: "era claro que las manifestaciones habían crecido a partir de las circunstancias internas. Durante ellas casi no hubo alusiones

66 "La tropa fue recibida a balazos por francotiradores, dijo García Barragán”, El Día, 3 de octubre de 1968 (Cano, 1998, p. 237). Díaz Ordaz mantuvo esta interpretación en entrevistas posteriores que dio a la prensa, señalando como hecho irrefutable la trayectoria de la bala que hirió al general José Hernández Toledo cuando iniciaba la refriega del 2 de octubre. Retrobetamx (12 de agosto de 2011). Entrevistas a Gustavo Díaz Ordaz en 1970 y 1977 [YouTube]. Recuperado de https://www.youtube.com/watch?v=a4P_L-QVfMA

${ }^{67}$ CIA Confidential cable. 3 de octubre de 1968. NSA, MP, TTMUSD. Recuperado de http://nsarchive.gwu.edu/NSAEBB/NSAEBB99/Doc74.pdf. Telegram from Freeman. 3 de octubre de 1968. NSA, MP, TTMUSD. Recuperado de http://nsarchive.gwu.edu/NSAEBB/ NSAEBB99/Doc19.pdf; Resumen. 4 de octubre de 1968. nSA, MP, TTMUSD. Recuperado de http://nsarchive.gwu.edu/NSAEBB/NSAEBB99/Doc77.pdf

\section{(이요}


anti-estadunidenses. Los estudiantes y algunos políticos han profundizado su descontento con la rigidez y corrupción del gobierno mexicano y la ineptitud con que han lidiado con las protestas en vísperas de los juegos olímpicos. ${ }^{168}$ En cambio, un informe del embajador Freeman básicamente coincidía con la cia local. Afirmaba que la hipótesis más plausible era que pequeños grupos extremistas bien organizados hubieran operado a la sombra del masivo movimiento estudiantil, que había sido moderado en su mayor parte. Reportaba que Díaz Ordaz le había dicho al congresista Armistead Selden hijo que los grupos de orientación maoísta, castrista y trotskista ocupaban los lugares más prominentes en el liderazgo estudiantil y habían dejado atrás a los comunistas pro soviéticos. Freeman creía que el gobierno había permitido el mitin para aprehender a los líderes radicales y no podía asegurar que no hubiese actuado con violencia. ${ }^{69}$ Repetía la versión oficial en el sentido de que hubo grupos estudiantiles bien armados situados en los edificios que rodeaban la plaza y que era posible que hubieran fraguado esta emboscada para provocar la respuesta armada del ejército frente a la prensa internacional que había llegado a la capital en vísperas de la olimpiada. Pero reconocía que a fin de cuentas no estaba claro si fueron los estudiantes extremistas o los agentes de seguridad quienes iniciaron el fuego. Concluía afirmando que el gobierno siempre había usado la conspiración extranjera como chivo expiatorio para distraer la atención de los problemas locales y que era posible que usara este argumento para desacreditar al movimiento. ${ }^{70}$

Si bien el interés primordial de Washington se relacionaba con la certeza que necesitaba de que México sería un lugar seguro para sus conciudadanos -tanto atletas como espectadores-durante la olimpiada, la brutal matanza les preocupaba por su potencial desestabilizador. Rostow envió a Johnson un memorándum donde resumía las ideas de la CIA sobre los hechos, pero añadía el mensaje que le había enviado Díaz Ordaz a través de Bruno Pagliai, hombre de negocios mexicano muy cercano al régimen, de visita en Washington: la paz se restablecería y las olimpiadas marcharían, los motines fueron planeados por extranjeros, las armas usadas eran nuevas y tenían sus números de serie y los grupos castristas y maoístas a los que se unieron los soviéticos de último momento, para no ser tachados de cobardes,

${ }^{68}$ CIA. Memorandum. 5 de octubre de 1968, caja 60, fólder 6, 56 a . LBJ, NSF, CFLAM.

${ }^{69}$ Confidential Telegram from Freeman to the Department of State. Octubre de 1968, caja 60 , fólder $760^{\mathrm{a}}$. LBJ, NSF, CFLAM.

${ }^{70}$ Confidential Telegram from Freeman to the Department of State. Octubre de 1968, caja 60 , fólder $760^{\mathrm{a}}$. LBJ, NSF, CFLAM.

\section{()(1) $\$$}


eran los responsables de los sucedido. ${ }^{71}$ Es posible que Díaz Ordaz exagerara la participación de extranjeros para deslindarse de sus errores, pero también para asegurar el respaldo de Washington.

La oficina de Inteligencia e Investigación del Departamento de Estado enfatizaba que el gobierno había cambiado de estrategia varias veces desde que inició el conflicto hasta culminar con lo sucedido en Tlatelolco.

El gobierno ha buscado culpar a los comunistas y ha anunciado periódicamente que participan elementos extranjeros. Pero no ha mostrado evidencia que sustente sus dichos. La administración parece no darse cuenta que los extremistas, aun con la ayuda de elementos extranjeros, difícilmente podría sostener una inconformidad por un periodo de tiempo tan dilatado si la insatisfacción estudiantil no fuera profunda y extendida [...]

Parece improbable que el PRI consiga encontrar una solución al problema sin cambiar la extendida convicción de que está atrincherado, paralizado y de que sólo busca ventajas para sí mismo. [...] El actual liderazgo no parece estar dispuesto a comprender la magnitud del problema de la alienación estudiantil, ni a aceptarla como una seria advertencia de que el partido no está respondiendo a las necesidades legítimas de un segmento de la sociedad mexicana crecientemente vociferante. ${ }^{72}$

El consejero político de la embajada, Wallace W. Stuart, ante las presiones de sus superiores en Washington, fue el primero en poner en duda que los estudiantes iniciaron el fuego, afirmando que era difícil saber quién lo había hecho. Defendió al embajador argumentando que había recibido información inexacta y que la propia cia tenía quince versiones diferentes sobre el asunto. ${ }^{73}$ Los informes de la estación de la cia local replicaron la información oficial asegurando que los jóvenes iniciaron la provocación en Tlatelolco. Scott mostró en ellos su apego a la información que recibía de los altos mandos del gobierno mexicano, comprometiendo la seriedad de su trabajo ante la falta de confirmación independiente (Morley, 2010, p. 358).

${ }^{71}$ White House secret memorándum. 5 de octubre de 1968. NSA, MP, TTMUSD. Recuperado de http://nsarchive.gwu.edu/NSAEBB/NSAEBB99/Doc102.pdf

${ }^{72}$ Bureau of Intelligence and Research, confidential intellligence note. 10 de octubre de 1968, NSA, MP TTMUSD. Recuperado de http://nsarchive.gwu.edu/NSAEBB/NSAEBB99/ Doc39.pdf

${ }^{73}$ US Embassy Confidential Letter. 18 de octubre de 1968. NSA, MP TTMUSD. Recuperado de http://nsarchive.gwu.edu/NSAEBB/NSAEBB99/Doc20.pdf

\section{()(1) $\$$}


Por su parte, la oficina de Inteligencia del Departamento de Defensa concluyó en un largo informe que el ejército había sobrerreaccionado, tal vez preocupado por acabar con los disturbios antes que iniciara la olimpiada; que posiblemente nunca se sabría quien comenzó el tiroteo y que la tropa actuó desordenadamente en lugar de centrarse en eliminar a los francotiradores, luego de que fue herido su comandante José Hernández Toledo. ${ }^{74}$

En contraste con la información de la cia y el embajador Freeman, un reporte del FBI, dirigido por Edgar Hoover a la Casa Blanca, afirmaba que una fuente infiltrada en la Liga Comunista Espartaco, entre cuyos integrantes había trotskistas y maoístas, afirmaba que habían formado la Brigada Olimpia como un grupo de choque. Este había desplegado francotiradores para asesinar al general José Hernández Toledo. Esta misma fuente aseguraba que los espartaquistas tenían contacto con la guerrilla guatemalteca y con trotskistas cubanos en México que les proveyeron armas para estas acciones "terroristas". ${ }^{75}$ Otra fuente señalaba que los soldados habían fumado mariguana, "actuado como locos y disparado salvajemente". ${ }^{76}$

En respuesta a las preguntas del Consejero de Seguridad Nacional de Johnson sobre lo sucedido en México, la cia verificó que no había evidencia de que se hubieran usado rifles provenientes de China; no existían pruebas concluyentes sobre la participación de agentes extranjeros en el movimiento, ni tampoco de que los estudiantes hubieran recibido armas. En cuanto a la formación de la Brigada Olimpia por parte de grupos trotskistas, afirmó que estos en efecto habían formado una brigada que se había disuelto en pequeñas células y que planeaba dinamitar torres de transmisión y colocar bombas durante los juegos olímpicos. ${ }^{77}$

Un balance general del conflicto estudiantil fue enviado por Freeman al Departamento de Estado casi dos semanas después de los hechos de Tlatelolco. En él afirmaba que este se había convertido en uno de los más serios disturbios civiles de las últimas dos décadas, y hacía un recuento de los

${ }^{74}$ Department of Defense Intelligence Report. 18 de octubre de 1968. NSA, MP TTMUSD. Recuperado de http://nsarchive.gwu.edu/NSAEBB/NSAEBB99/Doc88.pdf

${ }^{75}$ Es interesante señalar que la Secretaría de la Defensa creó el Batallón Olimpia. Marcelino García Barragán declaró que el "Batallón Olímpico" se había desplegado en los edificios donde se celebrarían las olimpiadas para resguardar los edificios. "El ejército no desea conservar por tiempo indefinido los planteles", El Día, 20 de septiembre de 1968 (Cano, 1998, p. 183).

${ }^{76}$ Informe confidencial del FBI. 5 de octubre de 1968, caja 60, fólder 7, 71d. LBJ, NSF, CFLAM.

${ }^{77}$ Memorandum for Walter Rostow. 9 de octubre de 1968, caja 60, fólder 7, 74 y 74a ${ }^{\mathrm{a}}$ LBJ, NSF, CFLAM.

\section{()(1) $\$$}


muertos y heridos en las diferentes etapas en las que dividía al movimiento. Reconocía que había dos versiones sobre quién había iniciado los disparos, si habían sido los estudiantes o los agentes de la ley, en "el más sangriento incidente desde que iniciaron los disturbios estudiantiles en julio", con un número incierto de muertos, heridos y 1500 arrestados. $^{78}$

Como se puede apreciar, los partes de la cia local fallaron al dar cuenta de lo sucedido el 2 de octubre al replicar la información de sus fuentes mexicanas. Lo mismo sucedió al embajador Freeman, en tanto que el FBI reportaba información menos confiable. Pero la ciA en Washington no secundó la versión de que habían sido extranjeros infiltrados los que iniciaron el fuego, y pronto el Departamento de Estado pidió una confirmación a las oficinas de México sobre la participación de aquellos. Era crucial para la seguridad estadunidense saber si había agentes comunistas de países enemigos actuando en el movimiento de un vecino con el que compartía 3185 kilómetros de frontera. Al final todos coincidieron en que no hubo participación de infiltrados extranjeros y que lo sucedido había dañado la imagen de México "como el país más progresista y estable de América Latina". Les pareció repudiable que el gobierno recurriera "al fantasma de que los elementos extranjeros y los comunistas locales eran los responsables del activismo estudiantil". ${ }^{79}$

Una vez que retornó la tranquilidad al país, se difuminaron los rumores que corrían sobre un posible golpe de Estado o un estallido revolucionario en la capital del país y cesaron las pérdidas que el Banco de México sufrió en sus reservas en esos días de zozobra. ${ }^{80}$ Estados Unidos comprobó que el régimen mexicano no estaba en peligro de descarrilarse y se preocupó por establecer si México era un lugar seguro para que sus conciudadanos asistiesen a las olimpiadas (Agee, 1987, p. 396). ${ }^{81}$ Transcurridos los días y semanas, confirmaron que el régimen mantenía el control sobre todo el país y consideraron cerrado el conflicto.

${ }^{78}$ Telegram from Freeman to the Department of State. 20 de octubre de 1968. NSA, MP, TTMUSD. Recuperado de http://nsarchive.gwu.edu/NSAEBB/NSAEBB99/Doc21.pdf

${ }^{79}$ Oficina de Inteligencia e Investigación, Departamento de Estado. Working Draft. 15 de noviembre de 1968. NSA, MP, TMDUSD. Recuperado de http://nsarchive.gwu.edu/NSAEBB/NSAEBB10/docs/doc26.pdf

80 The President's Daily Brief. 5 de octubre de 1968 (CIA, PDB). Recuperado de https:// www.cia.gov/library/readingroom/docs/DOC_0005976393.pdf

${ }^{81}$ Al gobierno estadunidense le interesaban especialmente los Juegos Olímpicos porque durante ellos la ciA realizaba tareas para reclutar espías y facilitar la salida de atletas de Europa del Este que solicitaran asilo político a los Estados Unidos.

\section{()(1) $(3$}


En suma, lo que se desprende de los informes de la embajada en México, la cia local y en Washington, el Departamento de Estado y el Departamento de Defensa sobre Tlatelolco, es que se alejaron de la versión oficial al sostener que no era posible establecer quién había iniciado los disparos. La CIA afirmó que no podía comprobar que los estudiantes hubieran recibido armas foráneas. La oficina de Inteligencia del Departamento de Defensa atribuyó el desorden del ejército durante el 2 de octubre a que su comandante fue herido. Todas las agencias de seguridad, salvo el FBI, coincidieron en que las acusaciones del gobierno de que agentes externos infiltrados causaron el movimiento y montaron la provocación el 2 de octubre eran falsas.

En 1998, treinta años después del 68, Javier García Paniagua, hijo del general Marcelino García Barragán -secretario de Defensa del gobierno de Díaz Ordaz-, entregó unos documentos al periodista Julio Scherer en los que su padre responsabilizó al entonces presidente y a su jefe del Estado Mayor Presidencial, Luis Gutiérrez Oropeza, de haber introducido en Tlatelolco a un cuerpo de elite paramilitar, formado y entrenado a instancias del propio Estado Mayor, para que iniciara la provocación, ubicándolos como francotiradores vestidos de civil, portando ametralladoras, en los departamentos y las azoteas de las construcciones que rodeaban la plaza. Según esta versión, este grupo de diez personas disparó indiscriminadamente contra el ejército y la población civil poco después de iniciado el mitin con objeto de sembrar el terror y acabar con la movilización, y actuó, aseguró García Barragán, sin que él tuviera conocimiento. El general aseveró que el Batallón Olimpia participó en la acción de Tlatelolco bajo su control, para evitar que huyeran los líderes estudiantiles a quienes querían aprehender (Scherer y Monsiváis, 2003, pp. 41-42 y 48-49). Los miembros de este cuerpo del ejército iban vestidos de civil y llevaban como distintivo un guante o pañuelo blanco en la mano, al igual que los agentes de la DFS y de la DGIPS que actuaron conjuntamente para detener a los líderes del movimiento (Aguayo, 1998, p. 223; Guevara, 2004, pp. 323-324).

Un estudio minucioso de la información aportada por García Barragán, elaborado por Carlos Montemayor (2000, p. 87), junto con información desclasificada que hizo pública The National Security Archive en 1998, concluye que no hay documentación que pruebe si fue una acción concertada por García Barragán, Díaz Ordaz y Gutiérrez Oropeza o si efectivamente fue una trampa tendida por este último con conocimiento del presidente. ${ }^{82}$

82 Algunos líderes del movimiento aseguran que el Batallón Olimpia disparó contra la multitud. Véase Jiménez (2011, p. 166).

\section{()(1) $\$$}


No obstante, añade que mientras no existan desmentidos o más documentos sobre lo dicho por García Barragán, tendríamos que aceptar su versión. El Departamento de Inteligencia del Departamento de Defensa estadunidense refiere que hubo roces entre el general García Barragán y el general Gutiérrez Oropeza porque este, junto con el general Mario Ballesteros Prieto -jefe del Estado Mayor de la Secretaría de la Defensa- desobedecieron sus órdenes la noche de Tlatelolco. Esta información podría abonar la versión de que el secretario de la Defensa no conocía los planes elaborados para el 2 de octubre. ${ }^{83}$

No existen testimonios publicados hasta hoy escritos por Díaz Ordaz sobre lo sucedido en 1968. Declaró a la prensa en 1977 que con sus actos había salvado al país. ${ }^{84}$ En unas memorias inéditas del presidente que Enrique Krauze (1997, p. 366) cita, Díaz Ordaz culpa a los comunistas infiltrados, a la iglesia, al MURo, al Opus Dei y al PAN de haber manipulado y haberse beneficiado del movimiento. La respuesta dada la tarde del 2 de octubre muestra un patrón, retomaba acciones similares aplicadas contra la disidencia en Chilpancingo, Guerrero, el 30 de diciembre de 1960 y en San Luis Potosí el 15 de septiembre de 1961. En aquellas movilizaciones, que sucedieron mientras Díaz Ordaz era secretario de Gobernación, se utilizaron francotiradores para iniciar los disparos, que luego fueron atribuidos a los opositores (Aguayo 2001, pp. 135-136). La versión de Gutiérrez Oropeza (1996, pp. 2, 35-40 y 47), impregnada por un nacionalismo caricaturesco, afirma que atrás del movimiento estaban Estados Unidos y la Unión Soviética. Los primeros operaron a través de la cia porque querían controlar todas las riquezas del país y lograr que la olimpiada cambiara de sede a la ciudad de Detroit, y la segunda porque, apoyada por Lázaro Cárdenas, quería convertir a México en un país comunista. Estos agitadores pagaron y movieron a los líderes como si se tratara de títeres y distribuyeron drogas entre los jóvenes. A estos promotores, afirma, se sumaron intelectuales y periodistas, así como los políticos resentidos con el ejecutivo porque no los incluyó en su gobierno o porque querían manipular la sucesión presidencial del siguiente año. Si nos atenemos a sus

${ }^{83}$ Department of Defense Intelligence Information Report. 14 de marzo de 1969. NSA, MP, TTMUSD. Recuperado de http://nsarchive.gwu.edu/NSAEBB/NSAEBB99/Doc91.pdf

${ }^{84}$ En una entrevista que le hicieron en abril de 1977 declaró a un periodista: "De lo que estoy muy orgulloso de esos seis años, es del año de 1968, porque me permitió servir y salvar al país, les guste o no les guste..." Retrobetamx (12 de agosto de 2011). Entrevistas a Gustavo Díaz Ordaz en 1970 y 1977. [YouTube]. Recuperado de https://www.youtube.com/ watch?v=a4P_L-QVfMA

\section{()(1) $\$$}


memorias inéditas, es factible que Díaz Ordaz haya compartido al menos parte de esta interpretación. Lo que es un hecho es que ambos personajes eran furiosos anticomunistas, autoritarios y que se atrincheraron en la teoría de la conjura para justificar sus actos y presentaron el movimiento del 68 como un producto de la confrontación bipolar y al país como una víctima de la guerra fría. No se puede descartar que el entonces presidente haya utilizado la teoría de esta burda conjura como una estrategia para disimular sus errores y su talante represor. ${ }^{85}$

Tal vez un colofón adecuado para apreciar cómo era percibido el gobierno mexicano post 68 lo proporciona un resumen semanal de la cia de los primeros días de 1969. En general, el informe era optimista en relación con que el gobierno pudiera enfrentar los retos por venir. Consideraba que los pequeños esfuerzos del presidente por liberalizar el gobierno habían intensificado las protestas a nivel local y malquistado a los políticos de la vieja guardia con el presidente. El informe dice:

Las marchas estudiantiles del verano pasado son la más grande manifestación de descontento contra el gobierno en tres décadas.

Pareciera que el sistema de partido político único en México, que ha sido tan efectivo en gobernar una sociedad atrasada y que trajo prosperidad y educación a muchos, le queda corto a un público crecientemente sofisticado y articulado [...]

La mayor parte de los numerosos informes que relacionan al movimiento con agentes subversivos políticos e ideológicos permanece sin demostrar. [...] Para octubre, el movimiento había alcanzado notoriedad internacional. Los estudiantes causaron los peores desórdenes civiles que México ha experimentado en veinte años y pusieron en peligro los Juegos Olímpicos [...] El incidente que de lejos y para todos los propósitos el final, sobrevino el 2 de octubre cuando estalló una balacera salvaje que mató a muchos e hirió a unas mil personas en un gran mitin en la Plaza de las Tres Culturas en Tlatelolco [...]

${ }^{85}$ Keller (2015, p. 216) afirma que Díaz Ordaz estaba convencido de que se trataba de una conjura comunista internacional. Por su parte, Pensado (2013, p. 231) sostiene que los principales representantes de las oficinas de seguridad mexicanas entendieron que ni la URSS ni Cuba estuvieron nunca involucradas en el movimiento. Sus afirmaciones se basan supuestamente en el texto de Aguayo sobre 1968, pero lo cierto es que este autor no sostiene lo dicho por aquel.

\section{(ㅇ)(1) $\$$}


El manejo oficial de la huelga [estudiantil] fue inepto [...] La ceguera oficial en torno a la verdadera disensión o a la protesta espontánea es en un sentido característica de México, donde los problemas internos son atribuidos a la agitación externa. [...] En los meses que siguieron a la crisis los funcionarios atribuyeron la culpa a Cuba, la URSS, China y a las agencias de seguridad estadunidenses [...] esta táctica desacreditó más al gobierno que a los estudiantes. ${ }^{86}$

Los materiales analizados muestran que ni la cia ni Estados Unidos fueron responsables de la represión que puso fin al movimiento del 68, como lo han sugerido Moctezuma (2008) y Mendoza (2007). Pese a las críticas al manejo de esta crisis por parte de la embajada, la cia en Washington y en México, el Departamento de Estado y el de Defensa, la administración de Johnson no dudó en respaldar al gobierno mexicano, quien era su aliado en la lucha contra el comunismo. Tampoco existe evidencia de que se trató de una conjura internacional instigada por agitadores extranjeros provenientes de Cuba, la URSS o China, como lo afirmó la versión oficial. De haber existido tal conjura, las agencias de seguridad la hubieran detectado, pues su tarea primordial -sobre todo después del triunfo de la revolución cubana- era monitorear el avance del comunismo en la región, y México era un lugar estratégico en la geopolítica de contención hemisférica. Considero que el análisis de la información aportada por los aparatos de seguridad estadunidenses, con todos sus matices y posturas encontradas, añade una nueva dimensión al conocimiento de las relaciones México-Estados Unidos, dimensión que incidió en las decisiones tomadas por la Casa Blanca. Para Washington, Díaz Ordaz mostró incompetencia para resolver el conflicto y por ello atribuyó lo sucedido a agitadores extranjeros. Pese a la imagen desfavorable del presidente mexicano, Johnson mantuvo su apoyo a este gobierno autoritario, como lo hizo con los militares golpistas latinoamericanos, porque era un aliado crucial en la confrontación de la guerra fría.

${ }^{86}$ CIA Secret intelligence summary. 17 de enero de 1969. NSA, MP TTMUSD. Recuperado de http://nsarchive.gwu.edu/NSAEBB/NSAEBB99/Doc83.pdf

\section{(ㅇ)(1) $\$$}


Desde sus primeros días el movimiento estudiantil fue monitoreado por las instancias de seguridad emplazadas en México, las cuales informaron a Washington sobre su devenir. El Departamento de Estado mostró un creciente interés sobre lo que sucedía a su vecino y a partir de agosto realizó análisis sobre la situación. En septiembre aumentaron las menciones a estos sucesos en el resumen diario sobre asuntos de seguridad que la CIA entregaba cotidianamente al presidente Johnson. Cuando escalaron las hostilidades, el movimiento pareció ganar adeptos entre otros grupos y el gobierno mexicano fue incapaz de controlar la movilización; a finales de septiembre, el Departamento de Estado pidió a Freeman que enviara un informe diario a Washington. El propio Rostow elaboró documentos para el presidente Johnson en donde le informaba sobre lo que sucedía en la ciudad de México.

De manera adicional a la inquietud por que la movilización estudiantil pudiera descarrilar al gobierno de Díaz Ordaz, a Washington también le preocupaba determinar si México era un lugar seguro para que viajaran los atletas y aficionados estadunidenses a los XIX Juegos Olímpicos. No hay que olvidar que en el contexto de la guerra fría estos juegos eran un importante escaparate de la competencia entre la URSS y Estados Unidos, una metáfora en la que los atletas de ambos bloques mostraban la superioridad de los sistemas políticos de sus respectivos países a través de sus triunfos.

También se aprecia en el presente trabajo que los informes de las distintas agencias de seguridad estadunidenses difieren en ocasiones. Las razones de estas divergencias ameritarían una investigación puntual que rebasa el alcance de este artículo. No obstante, es posible adelantar algunas explicaciones a estas disimilitudes con la documentación consultada. Los informes de la cia generados en Washington -salvo los resúmenes diarios para el presidente, que reproducían los dichos de la estación local de la ciason mucho más agudos y precisos, calidad que comparten con los realizados por el Departamento de Estado porque contaban con expertos calificados que tenían una visión continental y aun global de los sucesos. La agudeza y atinado análisis prospectivo de los informes elaborados por la oficina de inteligencia del Departamento de Estado sobresalen, así como los dosier de la CIA en Washington sobre la seguridad hemisférica. Los primeros fueron elaborados por diplomáticos de carrera y personal con experiencia en el análisis de inteligencia, con amplio conocimiento en los países de América Latina, y se nutrían de toda la información que recibían de sus funcionarios en la embajada, algunos de los cuales se dedicaban explícitamente a los asuntos

\section{()(1) $(9$}


de inteligencia. Los reportes confeccionados por la segunda también contaban con expertos de buen nivel y con una visión global. Es de subrayar que coincidieron las visiones del Departamento de Estado y la oficina de la CIA en Washington sobre el movimiento estudiantil. En cambio, los informes de la estación local de la ciA, que solían estar más apegados a la versión gubernamental mexicana por la cercanía con que trabajaban con los aparatos de seguridad locales, fueron menos atinados en coyunturas álgidas como el 2 de octubre. Por su parte, los pocos informes del Departamento de Defensa que pude consultar son muy escuetos, directos y mantienen distancia respecto al gobierno de Díaz Ordaz. Ellos fueron realizados por los agregados militares y sus fuentes seguramente provenían de integrantes de alto nivel de la Secretaría de la Defensa Nacional.

Asimismo, es posible detectar diferencias temporales en la información generada. Al inicio del movimiento, el 26 de julio, e inmediatamente después de Tlatelolco el embajador secundó la versión oficial. En el primer caso, admitiendo la participación de infiltrados extranjeros en los sucesos, aspecto en el que no coincidió con los informes de la cia local y, en el segundo, afirmando que los estudiantes habían iniciado la balacera, tema en el cual concordó con la cia local. Ante la urgencia de dar alguna explicación a Washington, sus primeras versiones se nutrieron de las interpretaciones de las autoridades y la prensa locales. Es plausible que la divergencia entre la embajada y la cia local al inicio de la movilización se haya debido a que ambas oficinas no compartieron su información antes de enviarla a sus superiores, pues existía rivalidad entre la cia local y la embajada. De acuerdo con su biógrafo (Morley, 2010), Scott se vanagloriaba de que las autoridades mexicanas preferían dirigirse a él antes que al embajador Freeman. Mientras que la embajada basaba sus informes en fuentes del gobierno y en la prensa, los de la cia local derivaban de altos funcionarios mexicanos incrustados en la administración, incluso el propio presidente, y de los informes que elaboraban las oficinas de seguridad mexicanas. El director de la DFS, Fernando Gutiérrez Barrios, quien figuraba como informante de la CIA como se señaló páginas atrás, seguramente compartía información con Scott. Luego de la masacre de Tlatelolco todos los informes de seguridad emanados de México replicaron la explicación oficial porque sus fuentes eran mexicanas, y no confirmaron sus interpretaciones con fuentes independientes. En especial, es de subrayarse la incapacidad de la CIA local de dar una versión propia a lo sucedido el 2 de octubre, error que, como se ha dicho (Morley, 2010), fue resultado de su cercanía con el gobierno de Díaz

\section{()(1) $\$$}


Ordaz, ${ }^{87}$ aunque también es posible suponer que Scott hubiese querido respaldar la versión de Díaz Ordaz para no arriesgar las actividades de espionaje y contraespionaje que realizaba su oficina en México. No obstante, a medida que transcurrieron los días, tanto el embajador como la cia local rectificaron en respuesta a las presiones de Washington y ya no secundaron la teoría de la conjura internacional sostenida por el gobierno mexicano. Pese a que México era un aliado importante en el contexto de la confrontación bipolar, no replicaron más la versión del presidente ni de los aparatos de seguridad mexicanos porque no pudieron comprobar la participación de comunistas extranjeros infiltrados, no confiaban en la factura de los informes de seguridad locales ni en la interpretación de Díaz Ordaz. La calidad de los informes mexicanos era mala en comparación con los de la cia local. Como señala Aguayo (2001, p. 133), quien ha revisado la documentación mexicana y parte de la estadunidense, los servicios locales eran muy precarios y cometieron severos errores de interpretación. Reproducían chismes y rumores y alimentaban la paranoia del presidente.

La visión sobre el movimiento estudiantil de 1968 constituye una paradoja, pues mientras los principales responsables de la represión insistieron en presentarlo como un escenario de la confrontación Este-Oeste y de la infiltración comunista extranjera en México, los funcionarios del Departamento de Estado, la cia y, en menor medida, el embajador, con excepción del FBI, consideraban que no existían pruebas de esa participación, y que el movimiento surgió como respuesta a las condiciones políticas autoritarias imperantes en el país y se había alimentado del descontento interno, si bien entre sus dirigentes había varios miembros de las izquierdas mexicanas. Esta divergencia contrasta con las visiones coincidentes previas sobre la guerra fría y la colaboración entre las agencias de seguridad de Estados Unidos y el gobierno de Díaz Ordaz, pese al cariz autonómico de la diplomacia mexicana hacia Cuba. Es posible que el presidente mexicano haya insistido en la conjura internacional para disimular su propia ineptitud, su autoritarismo y su negativa a aceptar que las causas del movimiento eran internas. ${ }^{88}$

${ }^{87}$ Doyle. The Tlatelolco Masacre. 10 de octubre de 2003 (National Security Archive, Mexico Project. The Tlatelolco Masacre) (Washington, D. C.). Recuperado de http:// nsarchive.gwu.edu/NSAEBB/NSAEBB99

${ }^{88}$ Coincidimos con Zermeño (1978, p. 47) en que el movimiento estudiantil fue "una protesta de sectores medios crecientes y en ascenso, una protesta en contra de la extralimitación con que la clase dirigente aprovechaba el margen que le ofrecía la estabilidad del orden

\section{()(1) $\$$}


En el ámbito mexicano, el movimiento estudiantil y el desprestigio que ocasionó al régimen han sido considerados por una corriente dominante de la historiografía como el fin del consenso autoritario y el inicio de la transición democrática. Paralelamente se ha construido una historia sobredeterminada por los relatos elaborados por los activistas mientras estuvieron en la cárcel (Jiménez, 2011, p. 207), en la que los estudiantes y sus líderes, y con ellos las izquierdas, se convirtieron en los portadores del cambio en México. Muchas de estas interpretaciones toman como marco la confrontación de la guerra fría, desestimando la multitud de matices que esta tuvo en cada uno de los países latinoamericanos. Aunque han surgido algunos trabajos distantes de esta discusión, como los de Jiménez, Rodríguez Kuri, Keller, Pensado y Zolov, que toman en consideración otros factores, la visión mitologizada sobre el 68 está aún a la espera de que más trabajos sobre estos acontecimientos puedan brindarnos una perspectiva renovada.

\section{LISTA DE REFERENCIAS}

Agee, P. (1987). La cIA por dentro, diario de un espía. Buenos Aires: Editorial Sudamericana.

Aguayo, S. (1998). Los archivos de la violencia. México: Reforma/Grijalbo.

Aguayo, S. (2001). La charola. Una historia de los servicios de inteligencia en México. México: Grijalbo.

Álvarez Garín, R. (1998). La estela de Tlatelolco. Una reconstrucción histórica del Movimiento estudiantil del 68. México: Grijalbo.

Brinkley, A. (2003). Historia de Estados Unidos. Un país en formación. México: McGraw Hill.

Cano Andaluz, A. (1998). 68, Antología periodística. México: Instituto de Investigaciones Bibliográficas-UNAM.

Cid Capetillo, I. (1998). Thomas C. Mann. En A. R. Suárez Argüello (coord.), En el nombre del Destino Manifiesto (pp. 314-326). México: Instituto Mora/Secretaría de Relaciones Exteriores.

Guevara Niebla, G. (2004). La libertad nunca se olvida. Memoria del 68. México: Cal y Arena.

Gutiérrez Oropeza, L. (1996). La realidad de los acontecimientos de 1968. [s. p. i.].

y en contra de la rigidez correlativa de un sistema institucional o político que veía llegar a su fin el acuerdo transitorio producido en un marco de relaciones sociales ya rebasado".

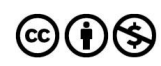


Hernández Rodríguez, R. (2000). La historia moderna del PRI, entre la autonomía y el sometimiento. Foro Internacional, xL(2), 278-306. Recuperado de http://foroin ternacional.colmex.mx/index.php/fi/article/view/1553/1543.

Herrera, O. y Santa Cruz, A. (2011). América del Norte. En M. de Vega (coord.), Historia de las relaciones internacionales de México, 1821-2010 (Vol. 1). México: Secretaría de Relaciones Exteriores.

Hodges, D. y Gandy, R. (2002). Mexico under siege. popular resistance to presidential despotism. Londres/Nueva York: Zed Books.

Jiménez Guzmán, H. (2011). El 68 y sus rutas de interpretación: una crítica historiográfica (Tesis de maestría inédita). Universidad Autónoma Metropolitana-Azcapotzalco, México.

Keller, R. (2015). Mexico's Cold War. Cuba, the United States, and the legacy of the Mexican Revolution. Nueva York: Cambridge University Press.

Krauze, E. (1997) La presidencia imperial. Ascenso y caída del sistema político mexicano (1946-1996). México: Tusquets.

Loaeza, S. (1988). Clases media y política en México. México: El Colegio de México.

Loaeza, S. (2005). Gustavo Díaz Ordaz: el colapso del milagro mexicano. En A. Bisberg y L. Meyer (coords.), Una historia contemporánea de México. Actores (vol. 2, pp. 117-155). México: Editorial Océano.

Mendoza, C. (2007). 1968. La conexión americana. Documental. México: Canal 6 de julio.

Meyer, L. (2004). La guerra fría en el mundo periférico: El caso del régimen autoritario mexicano. La utilidad del anticomunismo discreto. En D. Spenser (coord.), Espejos de la guerra fría. México, América Central y el Caribe (pp. 95-117). México: CIEsAs/Miguel Ángel Porrúa.

Meyer, L. (2010). Relaciones México-Estados Unidos. Arquitectura y montaje de las pautas de la guerra fría, 1945-1964. Foro Internacional, L(2), 202-242. Recuperado de http://forointernacional.colmex.mx/index.php/fi/article/view/1991/1981.

Moctezuma Barragán, P. (2008). El movimiento de 1968. Alegatos, 70, 311-340. Recuperado de http://www.azc.uam.mx/publicaciones/alegatos/inicio.php.

Montemayor, C. (2000). Rehacer la historia. Análisis de los nuevos documentos del 2 de octubre de 1968 en Tlatelolco. México: Editorial Planeta.

Morley, J. (2010). Nuestro hombre en México. Winston Scott y la historia oculta de la cIA. México: Editorial Taurus.

Niemeyer Jr., E. V. (1986). Personal diplomacy: Lyndon B. Johnson and Mexico, 19631968. The Southwestern Historial Quarterly 90(2), 159-186. Recuperado de http:// www.jstor.org/stable/30237015.

\section{(이요 $(3$}


Ojeda, M. (1984). Alcances y límites de la política exterior de México. México: El Colegio de México.

Pensado, J. (2013). Rebel Mexico, Student Unrest and Political Culture During the Long Sixties. Stanford: Stanford University Press.

Pettinà, V. (2016). Global horizons: Mexico, the Third World, and the Non-Aligned Movement at the time of the 1961 Belgrade Conference. The International History Review, 38(4), 741-764. DoI: http://dx.doi.org/10.1080/07075332.2015.1124906

Raat, W. D. (1987). US intelligence and covert action in Mexico, 1900-1947. Journal of Contemporary History, 22(4), 615-638. Recuperado de http://www.jstor.org/ stable/260813.

Riguzzi, P. y Ríos, P. de los (2012). Las relaciones México-Estados Unidos, 1756-2010, ¿Destino manifiesto? 1867-2010. Vol. II. México: IIH-UnAM.

Rodríguez Kuri, A. (2003). Los primeros días. Una explicación de los orígenes inmediatos del movimiento estudiantil de 1968. Historia Mexicana, LIII(1) 179-228. Recuperado de http://historiamexicana.colmex.mx/index.php/RHM/article/vie $\mathrm{w} / 1481$

Rojas, R. y Covarrubias, A. (2011). Caribe. En M. de Vega (coord.), Historia de las relaciones internacionales de México, 1821-2010. V. 3. México: Secretaría de Relaciones Exteriores.

Scherer García, J. y Monsiváis, C. (2003). Parte de guerra. Tlatelolco 1968, Documentos del general Marcelino García Barragán. Los hechos y la historia. México: Aguilar.

Suárez Argüello, A. R. (coord.) (1998). En el nombre del Destino Manifiesto. México: Instituto Mora/Secretaría de Relaciones Exteriores.

Torres, B. (2010). México y el mundo. Historia de sus relaciones exteriores, México y el mundo. De la guerra al mundo bipolar (t. viI). México: El Colegio de México.

Trejo Terreros, A. (2012). La mirada de Washington en el movimiento estudiantil de 1968. En A. del Castillo (coord.), Reflexión y crítica en torno al movimiento estudiantil de 1968. Nuevos enfoques y líneas de investigación (pp. 101-117). México: Instituto Mora.

Witherspoon, K. B. (2008). Before the eyes of the world. Mexico and the 1968 Olympic Games. Illinois: DeKalb.

Zermeño, S. (1978). México: Una democracia utópica. El movimiento estudiantil de 1968. México: Siglo XXI Editores.

Zolov, E. (2002). Rebeldes con causa. La contracultura mexicana y la crisis del Estado patriarcal. México: Editorial Norma.

Zolov, E. (2003). Toward an analytical framework for assessing the impact of the 1968 student movement on U.S.-Mexican relations. Journal of Iberian and Latin American Research, 9(2), 41-68. DoI: http://dx.doi.org/10.1080/13260219.2007.10418855

\section{()ㅜ(1) $(3$}




\section{OTRAS FUENTES}

Archivos

CIA, PDB. Central Intelligence Agency, Library, Electronic Reading Room, President's Daily Brief, 1961-1969 (Washington, D. C.). https://www.cia.gov/library/ readingroom/search/site/\%22President\%27s\%20Daily\%20Brief\%201961-1969\%22 DS, OH, sCAM. Department of State, Office of the Historian, Foreign Relations of the United States 1964-1968, vol xxxi, South and Central America; Mexico (Washington, D. C.), https://history.state.gov/historicaldocuments

LBJ, NSF, CFLAM. Lyndon B. Johnson Library, Materials at the LBJ Library, Pertaining to Latin America and the West Indies, National Security File, Country File, Latin America-Mexico (Austin, TX).

NSA, MP, L. The National Security Archive, The George Washington University, The Mexico Project (Washington, D. C.), http://nsarchive.gwu.edu/NSAEBB/NSAEBB204/index.htm

NSA, MP, TMDUSD. The National Security Archive, The George Washington University, The Mexico Project (Washington, D. C.), Tlatelolco Masacre Declasified U S Documents on Mexico and the Events of 1968, http://nsarchive.gwu.edu/NSAEBB/NSAEBB10/intro.htm

NSA, MP, TM. The National Security Archive, The George Washington University, The Mexico Project (Washington, D. C.), The Tlatelolco Masacre, http://nsarchive.gwu.edu/NSAEBB/NSAEBB99/

\section{Bibliografía}

Suárez Argüello, A. R. (1985). México, los Estados Unidos y el anticomunismo (19631968). Nuestra América, vi(16), 68-130.

Tasso, P. (2014). La historiografía oficial de 1968 (Tesis doctorado inédita). UAM-Azcapotzalco, México. 